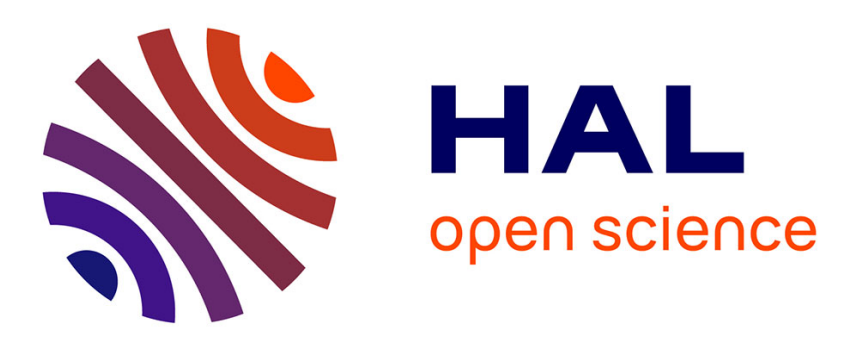

\title{
ENSO feedbacks and associated time scales of variability in a multimodel ensemble
}

\author{
Ali Belmadani, Boris Dewitte, S.-I. An
}

\section{To cite this version:}

Ali Belmadani, Boris Dewitte, S.-I. An. ENSO feedbacks and associated time scales of variability in a multimodel ensemble. Journal of Climate, 2010, 23 (12), pp.3181-3204. ISSN 0894-8755. 10.1175/2010jcli2830.1. hal-00766394

\section{HAL Id: hal-00766394 https://hal.science/hal-00766394}

Submitted on 10 Jun 2014

HAL is a multi-disciplinary open access archive for the deposit and dissemination of scientific research documents, whether they are published or not. The documents may come from teaching and research institutions in France or abroad, or from public or private research centers.
L'archive ouverte pluridisciplinaire HAL, est destinée au dépôt et à la diffusion de documents scientifiques de niveau recherche, publiés ou non, émanant des établissements d'enseignement et de recherche français ou étrangers, des laboratoires publics ou privés. 


\title{
ENSO Feedbacks and Associated Time Scales of Variability in a Multimodel Ensemble
}

\author{
Ali BelmadANi AND Boris DewitTe \\ Université de Toulouse, UPS (OMP-PCA), LEGOS, and IRD, LEGOS, Toulouse, France \\ SOON-IL AN \\ Department of Atmospheric Sciences/Global Environment Laboratory, Yonseï University, Seoul, South Korea
}

(Manuscript received 5 September 2008, in final form 28 January 2010)

\begin{abstract}
The background state of the equatorial Pacific determines the prevalence of a "slow" recharge oscillatortype ENSO over a "fast" quasi-biennial surface-driven ENSO. The first is controlled to a large extent by the thermocline feedback, whereas the latter is related to enhanced zonal advective feedback. In this study, dynamical diagnostics are used to investigate the relative importance of these two feedbacks in the Coupled Model Intercomparison Project and its relation with the differences in ENSO-like variability among the models. The focus is on the role of the mean oceanic surface circulation in controlling the relative weight of the two feedbacks.

By the means of an intermediate-type ocean model of the tropical Pacific "tuned" from the coupled general circulation model (CGCM) outputs, the contribution of the advection terms (vertical versus zonal) to the rate of SST change is estimated. A new finding is that biases in the advection terms are to a large extent related to the biases in the mean surface circulation. The latter are used to infer the dominant ENSO feedback for each CGCM. This allows for the classification of the CGCMs into three groups that account for the dominant feedback process of the ENSO cycle: horizontal advection (mainly in the western Pacific), vertical advection (mainly in the eastern Pacific), and the combination of both mechanisms.

Based on such classification, the analysis also reveals that the models exhibit distinctive behavior with respect to the characteristics of ENSO: for most models, an enhanced (diminished) contribution of the zonal advective feedback is associated with faster (slower) ENSO and a tendency toward a cooler (warmer) mean state in the western-to-central Pacific Ocean. The results support the interpretation that biases in the mean state are sustained/maintained by the privileged mode of variability associated with the dominant feedback mechanism in the models. In particular, the models having a dominant zonal advective feedback exhibit significant cold SST asymmetry (or negative skewness) in the western equatorial Pacific.
\end{abstract}

\section{Introduction}

The reliability of climate projections for the next century depends on the accuracy of coupled general circulation models (CGCMs) in representing the effect of the increasing concentration of greenhouse gases on the climate system at global and regional scales. It also depends on their ability to simulate realistic past and present climate variability and coupled ocean-atmosphere processes at different time scales. Of particular interest,

Corresponding author address: Ali Belmadani, Université de Toulouse, UPS (OMP-PCA), LEGOS, 14 Av. Edouard Belin, F-31400 Toulouse, France.

E-mail: ali.belmadani@ird.fr
El Niño-Southern Oscillation (ENSO) is the dominant source of interannual variability in the tropical climate system. It has been well known for its impacts on weather, ecosystems, and societies in the surrounding countries of the Pacific Ocean and even worldwide. Yet, a wide range of other coupled ocean-atmosphere modes of variability coexist at different time scales within the frequency spectrum of interannual variability: they range from near-annual (Jin et al. 2003; Kang et al. 2004) and quasi-biennial (Meehl 1987; Ropelewski et al. 1992) to decadal (Tourre et al. 1999; Zhang et al. 1999) time scales.

However, most CGCMs fail to reproduce such a rich spectrum (AchutaRao and Sperber 2002, 2006). This includes those from phase 3 of the Coupled Model Intercomparison Project (CMIP3) multimodel dataset, 
collected for the needs of the Intergovernmental Panel on Climate Change Fourth Assessment Report (IPCC AR4). In particular, many of them tend to produce a faster ENSO than observed, confined to the quasi-biennial time scale (Guilyardi et al. 2004). The tendency of a model to privilege one time scale of variability over the others has to be related to the basic dynamics of the coupled tropical Pacific system.

In this respect, some studies (An and Wang 2000; Wang and An 2001) have shown that the frequency of ENSO is dependent on the spatial structure of zonal wind stress anomalies, especially the longitudinal position of the westerly anomalies. An and Wang (2000) argue that the delayed oscillator theory (Suarez and Schopf 1988; Schopf and Suarez 1988; Battisti and Hirst 1989) only qualitatively describes the effect of the zonal location of the wind anomalies on the ENSO frequency: according to the authors, the time scales related to the negative feedback induced by equatorial wave dynamics (involving the propagation and reflection of Kelvin and Rossby waves) fail to reproduce the observed and modeled ENSO frequencies. Instead, the zonal position of the zonal wind stress anomalies directly influences the zonal currents in the central equatorial Pacific. As a result, the zonal advection of mean SST by the anomalous zonal currents, called the "zonal advective feedback," is involved. According to An and Wang (2000), the zonal advective feedback favors the transition of the ENSO cycle rather than the growth and consequently a shorter oscillation of 2-4 yr with a lower amplitude when the zonal wind stress is shifted westward. Conversely, when the zonal wind stress is shifted eastward, the zonal advective feedback favors the growth of the ENSO cycle rather than the transition and consequently a longer oscillation of 4-6 yr with a larger amplitude (An et al. 1999; An and Wang 2000).

Easterly wind anomalies can also influence the feedbacks of the ENSO cycle: for instance, the observed post-1970s central Pacific surface warming induced anomalous easterlies in the eastern Pacific as a result of the strengthening of the trade winds. This caused the mean upwelling to increase. As a result, the vertical advection of subsurface temperature by the mean upwelling, called the "thermocline feedback," was enhanced (Wang and An 2001). Consequently, the eastward migration of both SST anomalies associated with ENSO and anomalous surface zonal wind stress caused a prolongation of the ENSO period: indeed, such migration was associated with an increased oceanic adjustment time of recharge/ discharge (An and Wang 2000), accordingly to the recharge oscillator paradigm (Jin 1997a,b).

These results support the interpretation that the balance between the zonal advective feedback and the thermocline feedback-which are important contributors to the heat budget of the upper ocean in the Pacific basin (Hirst 1986) — is a key parameter in the determination of the structure and dynamics of the coupled ENSO mode and the frequency of the ENSO cycle. The two feedback mechanisms destabilize different leading coupled modes: whereas the thermocline feedback favors the "recharge oscillator mode" (Jin 1997a,b) characterized by a strong ENSO with a longer 4-6-year oscillation, the zonal advective feedback involves the "gravest ocean basin mode" (Jin and Neelin 1993) characterized by a weak ENSO with a shorter 2-4-year oscillation (An and Jin 2001).

On the other hand, Jin and An (1999) proposed an extension of the recharge oscillator model (Jin 1997a,b) which initially focused on the thermocline feedback alone and the slow dynamics of ENSO_-by including the zonal advective feedback in the SST equation. They show that both feedbacks are dynamically connected through the geostrophic balance between the upper-ocean zonal currents and the meridional gradient of the thermocline depth. They also show that the two feedbacks contribute in a similar way to the transition and growth of ENSO (see also An and Jin 2001; Kang et al. 2001). In fact, both feedbacks have to be taken into account in order to explain the main properties of ENSO (e.g., the simultaneous development of SST anomalies throughout the central to eastern Pacific), conversely to earlier theoretical studies that considered the zonal advective feedback alone (Picaut et al. 1997) or the thermocline feedback alone (Suarez and Schopf 1988; Jin 1997a,b).

An and Jin (2001) used the conceptual model of Jin and An (1999) to further explore the sensitivity of ENSO growth rate and frequency to the basic-state parameters that control the strength of the zonal advective feedback and the thermocline feedback. They showed that, whereas the thermocline feedback (zonal advective feedback) considered alone leads to eigenmodes in the low-frequency (high frequency) regime under $0.3 \mathrm{yr}^{-1}$ (above $1 \mathrm{yr}^{-1}$ ), the combined effect of both feedbacks on the frequency regime is sensitive to the mean state. This result is consistent with the observed change in ENSO frequency and amplitude after the late-1970s climate shift (An and Wang 2000; Wang and An 2001).

A similar approach making use of a simplified version of the Cane-Zebiak (CZ) coupled model (Zebiak and Cane 1987) was adopted by Fedorov and Philander (2001). They performed a stability analysis; that is, they studied the tendency of the model to favor one coupled mode of oscillation over the other in response to changes in basic parameters of the mean state: intensity of the trade winds, thermocline depth, and temperature difference across the thermocline. Their analysis revealed the existence of 2 types of unstable modes: the "delayed oscillator" 
mode with long oscillations ( $\sim 5 \mathrm{yr})$, driven by vertical movements of the thermocline as a result of the basinwide adjustment of the ocean to wind changes, and the "SST" mode with a shorter time scale ( $\sim 2 \mathrm{yr})$, controlled by advection and by entrainment across the thermocline. In spite of a slightly different formalism (including a focus on the importance of the mean thermocline rather than the mean upwelling), these results resemble those obtained by An and Jin (2001). They confirm the importance of the mean state and the associated balance between thermocline and zonal advective feedbacks upon ENSO frequency. In fact, both feedbacks coexist in the real world, which makes ENSO a hybrid coupled mode (Fedorov and Philander 2000).

Long-term CGCM simulations from an extensive multimodel dataset offer the opportunity to document the role of the balance between ENSO feedbacks in setting the time scale of ENSO variability and the characteristics of the mean state. Some recent studies have been dedicated to the understanding of the numerous biases in the mean state exhibited by CGCMs of the current generation (AchutaRao and Sperber 2006), which contribute to limit their current skill for climate change projections. The assessment of the stability of the models is particularly interesting as it provides material for the understanding of the models' biases and the characteristics of the simulated ENSO variability (Battisti and Hirst 1989; Jin and Neelin 1993; Fedorov and Philander 2001). For this purpose, most studies have been relying on statistical analyses from the model outputs in order to estimate the strength of the thermocline feedback versus the zonal advective feedback.

For instance, van Oldenborgh et al. (2005, hereafter VPC05) show that, among the CMIP3 simulations, the ones that present the higher-frequency ENSO cycle are the ones that have a weak east Pacific upwelling feedback loop (and consequently enhanced zonal advective cooling). In their formalism, the zonal advective feedback (thermocline feedback) is quantified from the linear regression between the rate of SST change and the zonal wind stress (thermocline depth) anomalies in the equatorial band (Burgers and van Oldenborgh 2003).

On the other hand, Guilyardi (2006, hereafter G06) proposes the concept of SST mode (S mode) and thermocline mode ( $\mathrm{T}$ mode) described by several authors (Hirst 1986; Neelin et al. 1998; Fedorov and Philander 2001) to classify the IPCC models in groups according to their privileged ENSO regime (S-mode regime or hybrid mode regime). His diagnostic, based on lag-correlation analyses between ENSO indices (Trenberth and Stepaniak 2001), allows separating westward and eastward propagations of SST anomalies. Indeed, the S mode, which is related to the zonal advective feedback, presents low-amplitude, high-frequency ENSO cycles with westward-propagating anomalies. On the other hand, the thermocline feedbackrelated $\mathrm{T}$ mode features high-amplitude, low-frequency ENSO cycles and eastward propagations. The dominant direction of propagation is determined by the effect of ocean-atmosphere coupling on equatorial Kelvin and Rossby wave dynamics, as underlined by Hirst (1986): the zonal advective feedback (thermocline feedback) tends to destabilize the first baroclinic mode Rossby wave (the Kelvin wave) and to damp the Kelvin wave (the first baroclinic mode Rossby wave), thus favoring westward (eastward) propagating features.

These statistical approaches provide meaningful pieces of information to understand the model biases and assess their realism. However, by construction, they do not explicitly resolve the underlying mechanisms responsible for the tendency of a model to favor one regime over the other. In addition, they do not consider nonlinearities that contribute to the feedback processes and can drastically imprint characteristics of the ENSO variability (Timmermann and Jin 2002).

In the present study, a different approach is proposed. It is based on the use of a simple dynamical ocean model tuned from the CGCMs to infer the feedback processes most responsible for the model biases. As a complement to the studies by VPC05 and G06, the focus is on the dominance of the zonal advective feedback over the thermocline feedback in the CGCMs. Our objectives are twofold: 1) investigate the relevance of dynamical regimes for classifying the IPCC models; 2) target the key physical processes responsible for the prevalence of one regime over the other in the CGCMs. Overall, we aim at providing a physical interpretation of the model simulations and indices to understand the models' responses to increased $\mathrm{CO}_{2}$ (and assess their relevance for the study of the impact of climate change on ENSO variability).

Similar diagnostics to the ones used by Dewitte et al. (2007a) to study ENSO variability are applied here to the CGCMs of the CMIP3 archive, extending their approach to a more comprehensive dataset. It is verified that in most cases, the too high (too low) ENSO frequency and the cold (warm) bias of the mean temperature state can be related to the overestimation (underestimation) of particular coupled feedback processes. This allows classifying the models in three relevant groups for the understanding of ENSO dynamics and the interpretation of biases: zonal advective feedback, thermocline feedback, and hybrid feedback-dominated models.

The paper is organized as follows. Section 2 is devoted to the presentation of the multimodel dataset and the reanalysis products used in this study. The methodology will also be detailed in this section. Section 3 describes 
TABLE 1. Description of the coupled models considered in this study. The run number is specified if there is more than one ensemble member (different initial conditions). Resolutions are given along the equator. Because of gaps in the data, some models show variables with different time spans.

\begin{tabular}{|c|c|c|c|c|c|}
\hline $\begin{array}{l}\text { Model } \\
\text { number }\end{array}$ & Model name & Modeling group & $\begin{array}{l}\text { Atmosphere } \\
\text { resolution }\end{array}$ & $\begin{array}{l}\text { Ocean } \\
\text { resolution }\end{array}$ & $\begin{array}{l}\text { Length of } \\
\text { simulation (yr) }\end{array}$ \\
\hline 1 & BCCR-BCM2.0 & $\begin{array}{l}\text { BCCR/Nansen Environmental } \\
\text { and Remote Sensing Center } \\
\text { (NERSC)/Geophysical Institute } \\
\text { (GFI) (Norway) }\end{array}$ & $1^{\circ} \times 1^{\circ} \mathrm{L} 31$ & $1^{\circ} \times 1^{\circ} \mathrm{L} 33$ & 155 \\
\hline 2 & CCCma CGCM3.1 & CCCma (Canada) & $3.75^{\circ} \times 3.71^{\circ} \mathrm{L} 31$ & $1.88^{\circ} \times 1.86^{\circ} \mathrm{L} 29$ & 155 \\
\hline 3 & CCCma CGCM3.1 (T63) & CCCma (Canada) & $2.81^{\circ} \times 2.79^{\circ} \mathrm{L} 31$ & $1.41^{\circ} \times 0.93^{\circ} \mathrm{L} 29$ & 155 \\
\hline 4 & CNRM-CM3 & Météo France/CNRM (France) & $2.81^{\circ} \times 2.79^{\circ} \mathrm{L} 45$ & $2^{\circ} \times 1^{\circ} \mathrm{L} 33$ & 150 \\
\hline 5 & CSIRO Mk3.0 (run 1) & CSIRO (Australia) & $1.88^{\circ} \times 1.86^{\circ} \mathrm{L} 18$ & $1.88^{\circ} \times 0.93^{\circ} \mathrm{L} 31$ & 134 \\
\hline 6 & CSIRO Mk 3.5 & CSIRO (Australia) & $1.88^{\circ} \times 1.86^{\circ} \mathrm{L} 18$ & $1.88^{\circ} \times 0.93^{\circ} \mathrm{L} 31$ & 134 \\
\hline 7 & GFDL CM2.0 & NOAA/GFDL (United States) & $2.5^{\circ} \times 2^{\circ} \mathrm{L} 24$ & $1^{\circ} \times 0.33^{\circ} \mathrm{L} 50$ & $\begin{array}{l}129(U) \\
150(T, S, \operatorname{SST}, \tau)\end{array}$ \\
\hline 8 & GFDL CM2.1 & NOAA/GFDL (United States) & $2.5^{\circ} \times 2.02^{\circ} \mathrm{L} 24$ & $1^{\circ} \times 0.33^{\circ} \mathrm{L} 50$ & 150 \\
\hline $9 \mathrm{a}$ & GISS-AOM (run 1) & NASA GISS (United States) & $4^{\circ} \times 3^{\circ} \mathrm{L} 12$ & $4^{\circ} \times 3^{\circ} \mathrm{L} 31$ & 155 \\
\hline $9 b$ & GISS-AOM (run 2) & NASA GISS (United States) & $4^{\circ} \times 3^{\circ} \mathrm{L} 12$ & $4^{\circ} \times 3^{\circ} \mathrm{L} 31$ & 155 \\
\hline 10 & GISS-EH & NASA GISS (United States) & $5^{\circ} \times 4^{\circ} \mathrm{L} 20$ & $1^{\circ} \times 1^{\circ} \mathrm{L} 33$ & 125 \\
\hline 11 & GISS-ER & NASA GISS (United States) & $5^{\circ} \times 4^{\circ} \mathrm{L} 20$ & $5^{\circ} \times 4^{\circ} \mathrm{L} 33$ & 104 \\
\hline 12 & IAP FGOALS-g1.0 (run 1) & LASG/IAP (China) & $2.81^{\circ} \times 2.79^{\circ} \mathrm{L} 26$ & $1^{\circ} \times 1^{\circ} \mathrm{L} 33$ & 155 \\
\hline 13 & INGV ECHAM4 & INGV (Italy) & $1.125^{\circ} \times 1.12^{\circ} \mathrm{L} 19$ & $1^{\circ} \times 1^{\circ} \mathrm{L} 33$ & 100 \\
\hline 14 & INM-CM3.0 & INM (Russia) & $5^{\circ} \times 4^{\circ} \mathrm{L} 21$ & $2.5^{\circ} \times 2^{\circ} \mathrm{L} 33$ & 134 \\
\hline 15 & IPSL CM4 & IPSL (France) & $3.75^{\circ} \times 2.54^{\circ} \mathrm{L} 19$ & $2^{\circ} \times 1^{\circ} \mathrm{L} 31$ & 147 \\
\hline 16 & MIROC3.2(hires) & $\begin{array}{l}\text { Center for Climate System } \\
\text { Research (CCSR)/National } \\
\text { Institute for Environmental } \\
\text { Studies (NIES)/Frontier } \\
\text { Research Center for Global } \\
\text { Change (FRCGC) (Japan) }\end{array}$ & $1.125^{\circ} \times 1.12^{\circ} \mathrm{L} 56$ & $1.125^{\circ} \times 0.56^{\circ} \mathrm{L} 33$ & 100 \\
\hline 17 & MIROC3.2(medres) & CCSR/NIES/FRCGC (Japan) & $2.81^{\circ} \times 2.79^{\circ} \mathrm{L} 20$ & $1.41^{\circ} \times 0.56^{\circ} \mathrm{L} 33$ & 150 \\
\hline 18 & MIUBECHOG & MIUB (Germany) & $3.75^{\circ} \times 3.71^{\circ} \mathrm{L} 19$ & $2.81^{\circ} \times 0.5^{\circ} \mathrm{L} 20$ & 147 \\
\hline 19 & MPI ECHAM5 & MPI (Germany) & $1.88^{\circ} \times 1.87^{\circ} \mathrm{L} 32$ & $1^{\circ} \times 1^{\circ} \mathrm{L} 40$ & 123 \\
\hline 20 & MRI CGCM2.3.2a & MRI (Japan) & $2.81^{\circ} \times 2.79^{\circ} \mathrm{L} 30$ & $2.5^{\circ} \times 0.5^{\circ} \mathrm{L} 23$ & 154 \\
\hline 21 & NCAR CCSM3.0 (run 2) & NCAR (United States) & $1.41^{\circ} \times 1.40^{\circ} \mathrm{L} 26$ & $1.125^{\circ} \times 0.27^{\circ} \mathrm{L} 40$ & 150 \\
\hline 22 & UKMO HadCM3 (run 1) & Met Office (United Kingdom) & $3.75^{\circ} \times 2.5^{\circ} \mathrm{L} 19$ & $1.25^{\circ} \times 1.25^{\circ} \mathrm{L} 20$ & 148 \\
\hline 23 & UKMO HadGEM1 & Met Office (United Kingdom) & $1.875^{\circ} \times 1.25^{\circ} \mathrm{L} 38$ & $1^{\circ} \times 0.34^{\circ} \mathrm{L} 40$ & $\begin{array}{r}78(U, T, S) \\
147(\mathrm{SST}, \tau)\end{array}$ \\
\hline
\end{tabular}

some characteristics of the ENSO mode in the multimodel ensemble, as well as the mean biases related to both zonal advective and thermocline feedbacks. Section 4 is a discussion, followed by concluding remarks in section 5 .

\section{Datasets and methodology}

\section{a. Datasets}

The multimodel ensemble used in this study is presented in Table 1. It consists of the CGCMs of the CMIP3 dataset that have provided enough data on 25 July 2007 through the IPCC data center at the Program for Climate Model Diagnosis and Intercomparison (PCMDI) or for some of them [Bjerknes Centre for Climate Research (BCCR) Bergen Climate Model, version 2.0 (BCM2.0);
Max Planck Institute (MPI) ECHAM5; and National Center for Atmospheric Research (NCAR) Community Climate System Model, version 3.0 (CCSM3.0)] directly from the modeling groups (for a part of the data at least).

The preindustrial control experiment (picntrl)-for which the concentration of greenhouse gases is fixed to estimates from 1850-was chosen in order to evaluate the performance of the models under past-present climate conditions for three main reasons: 1) this experiment is the one that provides the longest time series and thus the best statistical confidence, 2) the fixed external forcings for long time series make these simulations appropriate for the study of the physical mechanisms of natural climate variability, and 3) make the analyses at interannual to decadal scales much easier to conduct [no need to remove the trend as in the climate of the twentieth century experiment $(20 \mathrm{c} 3 \mathrm{~m})$, for instance]. Monthly 
outputs were used since we focus on low-frequency mechanisms.

CMIP3 model outputs were compared to those provided by the Simple Ocean Data Assimilation (SODA) reanalysis project, an ongoing effort to reconstruct historical ocean climate variability on space and time scales similar to those captured by the atmospheric reanalysis projects. In this paper, we used the monthly outputs of SODA 1.4.2 version. SODA uses an ocean general circulation model (OGCM) based on the Parallel Ocean Program numerics (Smith et al. 1992), with a $0.25^{\circ} \times 0.4^{\circ}$ horizontal resolution at the equator and 40 vertical levels with 10-m spacing near the surface. The constraint algorithm is based on optimal interpolation data assimilation. Assimilated data includes temperature and salinity profiles from the World Ocean Database 2001 [mechanical bathythermograph (MBT), XBT, CTD, and station data], as well as additional hydrography, SST, and altimeter sea level. The model was forced by daily surface winds provided by the 40-yr European Centre for Medium-Range Weather Forecasts (ECMWF) Re-Analysis (ERA-40) (Uppala et al. 2005) for the 44-yr period from 1 January 1958 to 31 December 2001. Surface freshwater flux for the period 1979-present were provided by the Global Precipitation Climatology Project monthly satellite-gauge merged product (Adler et al. 2003) combined with evaporation obtained from the same bulk formula used to calculate latent heat loss. The reader is invited to refer to Carton et al. (2000) and Carton and Giese (2008) for a more detailed description of the SODA system.

To assess the realism of the chosen reference, CMIP3 model outputs were also compared to those from the National Centers for Environmental Prediction (NCEP) Global Ocean Data Assimilation System (GODAS) (Behringer and Xue 2004). Like SODA, GODAS is a global ocean reanalysis, but it covers a shorter period, from 1980 to 2007. It is based on the Geophysical Fluid Dynamics Laboratory (GFDL) Modular Ocean Model version 3 (Pacanowski and Griffies 2000), with a $1^{\circ}$ zonal $\times$ $1 / 3^{\circ}$ meridional resolution at the equator and 40 vertical levels with $10-\mathrm{m}$ spacing near the surface. The threedimensional variational data assimilation scheme originally designed by Derber and Rosati (1989) was modified to include salinity profiles [derived from temperature profiles using a local temperature-salinity $(T-S)$ climatology based on the World Ocean Database 1998]. Assimilated data also include temperature profiles from XBT, Tropical Atmosphere Ocean (TAO), Triangle Trans-Ocean Buoy Network (TRITON), and Prediction and Research Moored Array in the Tropical Atlantic (PIRATA) moorings and from Argo profiling floats. Momentum, heat, and freshwater fluxes are from the NCEP atmospheric reanalysis 2 (Kanamitsu et al. 2002).
The National Oceanic and Atmospheric Administration (NOAA) Extended Reconstructed Sea Surface Temperature (ERSST) version 3 monthly data, available on a $2^{\circ}$ global grid (Smith et al. 2008), was used to provide a third independent estimate for the length of the ENSO cycle. This dataset covers the 129-yr 1880-2008 period.

b. Method

\section{1) Diagnosing the ENSO MOde}

The ENSO mode was diagnosed from the results of the singular value decomposition (SVD; e.g., Bretherton et al. 1992) between the SST and wind stress anomalies in the tropical Pacific Ocean $\left(11^{\circ} \mathrm{S}-11^{\circ} \mathrm{N}\right)$ over the whole available time period (Table 1). The term "anomalies" used in this paper refers to the monthly model outputs from which monthly climatology has been removed.

The period of the ENSO cycle is defined here as the period associated with the dominant significant peak in the 1- to 10-yr frequency range of the fast Fourrier transform (FFT) power spectrum of the time series associated with the first SVD mode for SST anomalies. The statistical significance of such peak was assessed against red noise level with the same lag-1 autocorrelation (Torrence and Compo 1998). The spectrum was computed by ensemble averaging the spectra obtained from a 20 -yr running window ( $15 \mathrm{yr}$ for the reanalysis products that span a shorter period) with a $50 \%$ overlapping factor and Hann filtering in order to increase the number of degrees of freedom and thus gain statistical confidence in the detected peaks.

The only drawback of this method is that the frequency axis of the resulting smoothed spectrum has a low resolution in the interannual band: this implies wide error bars for the obtained estimates of the ENSO period. To reduce significantly such uncertainty, the running window used to compute the spectra would need to be, say, 5 times wider. This would require 500 -yr simulations from the multimodel ensemble, whereas only $100-150 \mathrm{yr}$ of data were available for most CGCMs. Another issue related to the relatively short length of the simulations is that centennial-scale ENSO modulation is ignored. Yet, it has been recently shown to have a significant influence on the spectral properties of ENSO in a 2000-yr simulation of the GFDL Climate Model version 2.1 (CM2.1) (Wittenberg 2009). Caution is therefore needed for the interpretation of the results from the FFT analysis performed here, as discussed in section 3c. The values for the ENSO period are expected to be slightly larger than the ones obtained from the Niño-3 SST index (G06): indeed, the geographical domain used for this study has a wider meridional extension and thus 


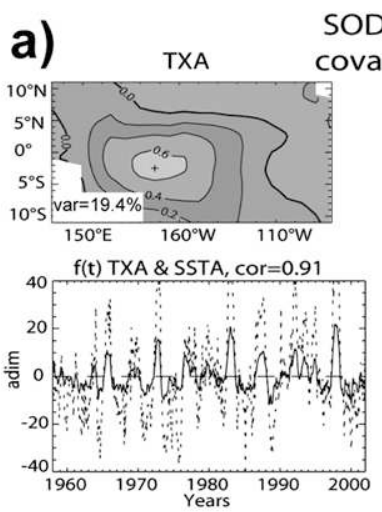

SODA-1.4.2 covar $=86.3 \%$
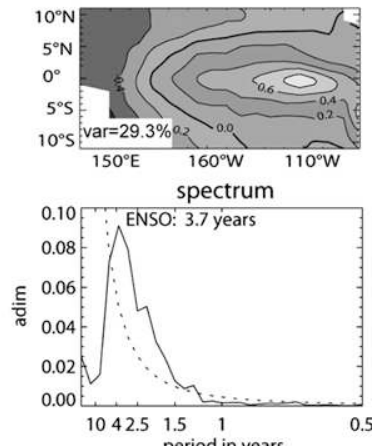

period in years
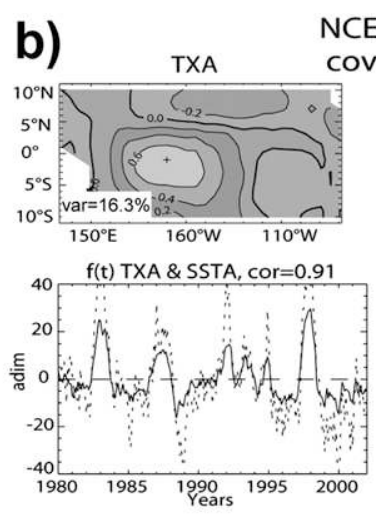

SSTA

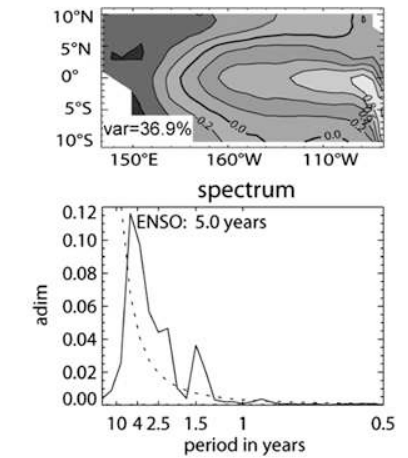

NCEP-GODAS covar $=85.8 \%$$$
\text { 影 }
$$
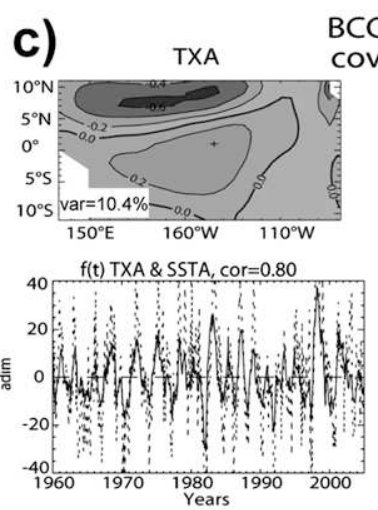

BCCR-BCM2.0 Covar $=87.0 \%$
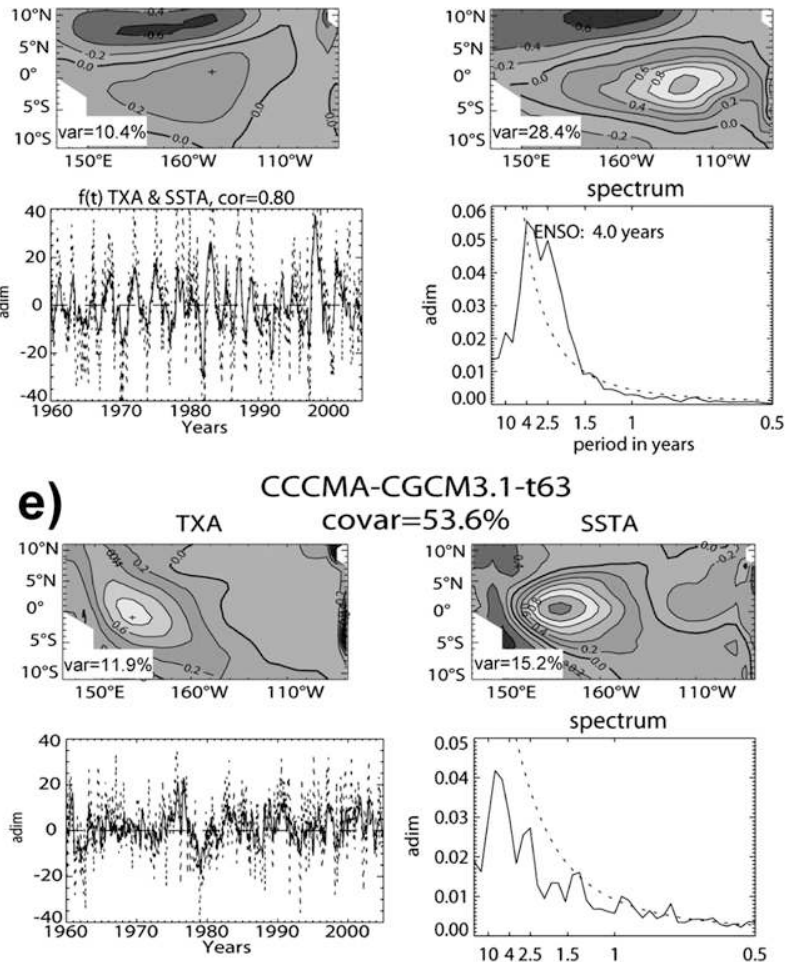

MA-CGCM3.1-t63
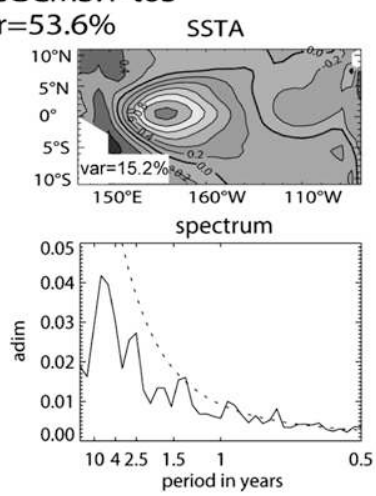
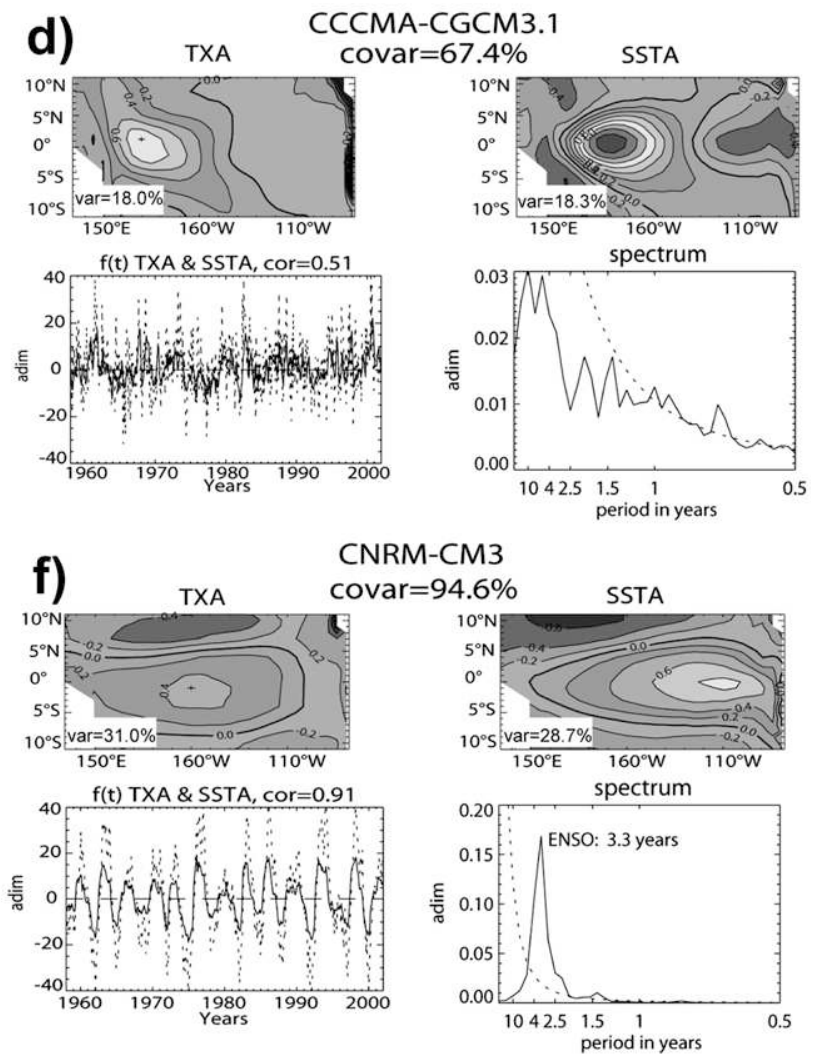

FIG. 1. First SVD mode between wind stress and SST anomalies $\left(11^{\circ} \mathrm{S}-11^{\circ} \mathrm{N}, 134^{\circ} \mathrm{E}-81^{\circ} \mathrm{W}\right)$ : (a) SODA 1.4 .2 , (b) NCEP GODAS, (c) BCCR-BCM2.0, (d) CCCma CGCM3.1 (T47), (e) CCCma CGCM3.1 (T63), (f) CNRM-CM3, (g) CSIRO Mk3.0, (h) CSIRO Mk3.5, (i) GFDL CM2.0, (j) GFDL CM2.1, (k) GISS-AOM (run 1), (1) GISS-AOM (run 2), (m) GISS-EH, (n) GISS-ER, (o) IAP FGOALS-g1.0, (p) INGV ECHAM4, (q) INM-CM3.0, (r) IPSL CM4, (s) MIROC3.2(hires), (t) MIROC3.2(medres), (u) MIUBECHOG, (v) MPI ECHAM5, (w) MRI CGCM2.3.2a, (x) NCAR CCSM3.0, (y) UKMO HadCM3, (z) UKMO HadGEM1. For each model, from left to right and top to bottom: spatial patterns for zonal wind stress and SST anomalies, associated adimensionalized time series (full line for SST anomalies, dashed line for wind stress anomalies), and the corresponding frequency spectra adimensionalized by the energy integrated over the whole frequency domain (full line for SST anomalies, dashed line for red noise). Contour interval (CI) $=0.2$ units. Spatial patterns are adimensionalized by their respective variance over the domain and multiplied by 10 . The location of maximum variance in wind stress anomalies is indicated by a cross on the map of the associated SVD mode. Percentage of explained variance for SST and zonal wind stress are indicated on the corresponding panels. Percentage of explained covariance is also provided. Correlation value between time series is indicated above the corresponding panel and the dominant ENSO period is indicated on the spectrum plot. Time series are shown over a 45 -yr period for the CGCMs and over the available time span for the reanalyses. 


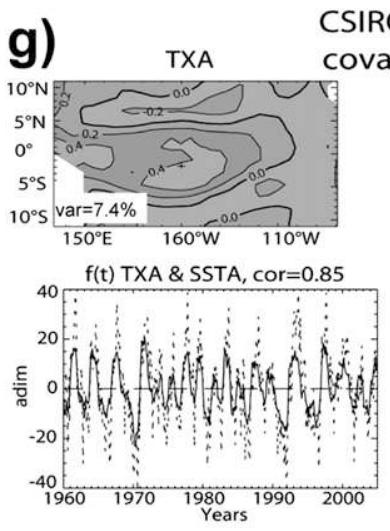

CSIRO-MK3.0
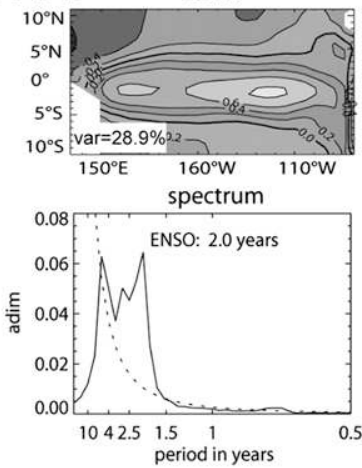

i)

TXA

GFDL-CM2.0
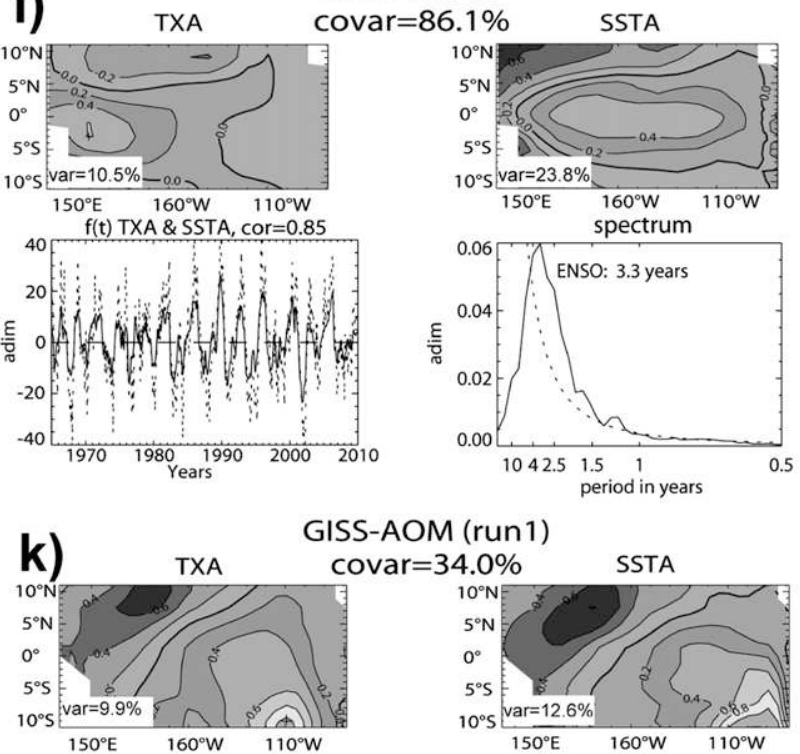

GISS-AOM (run 1) covar $=34.0 \%$
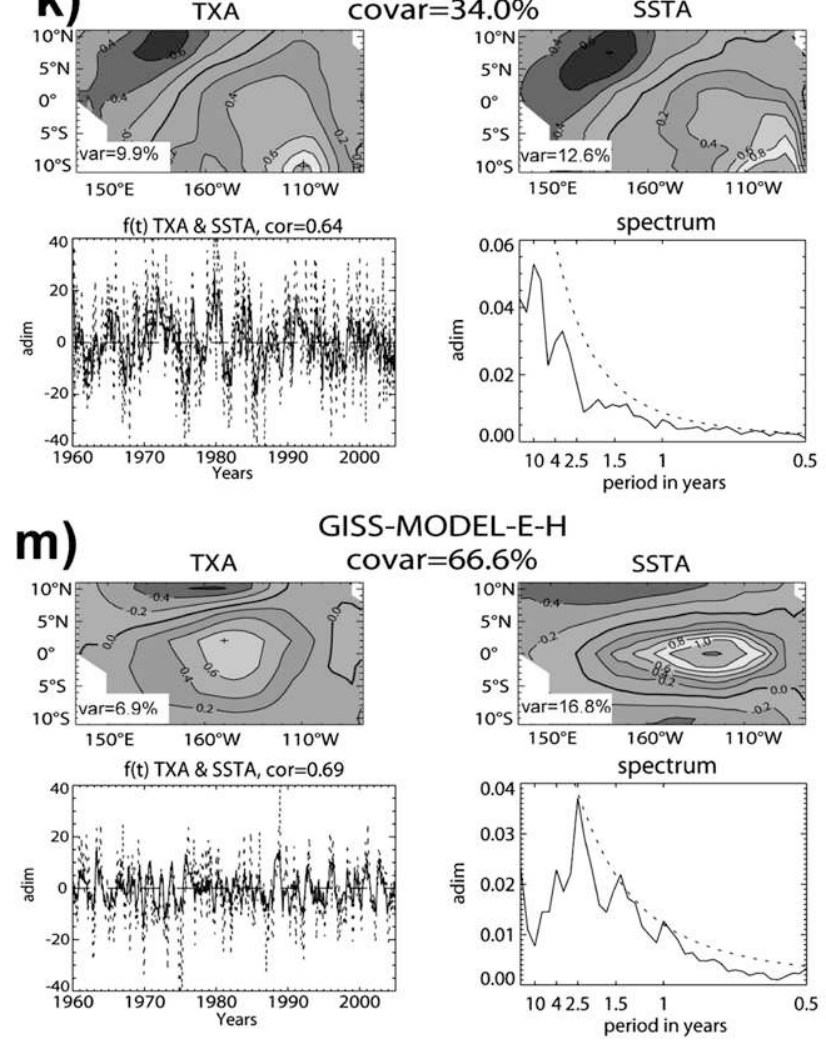
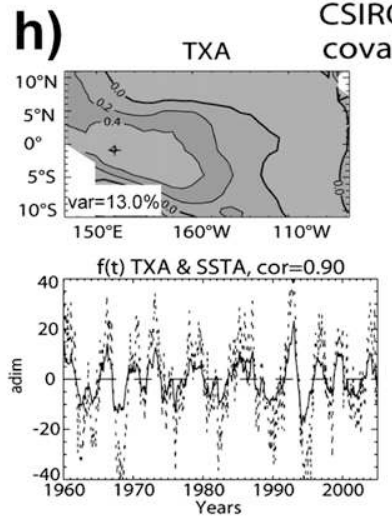

CSIRO-MK3.5

ovar $=88.4 \%$
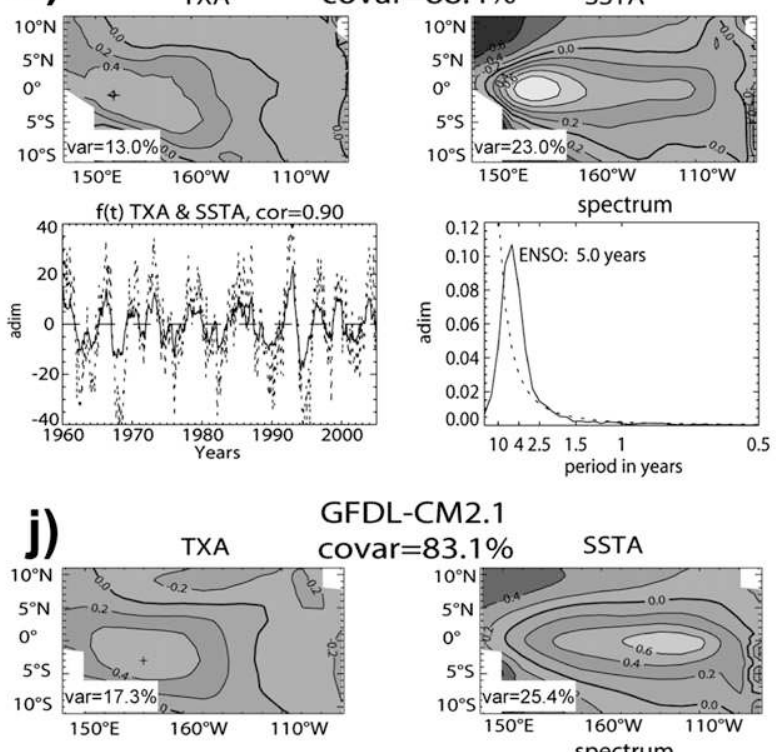

GFDL-CM2.1

covar $=83.1 \% \quad$ SSTA
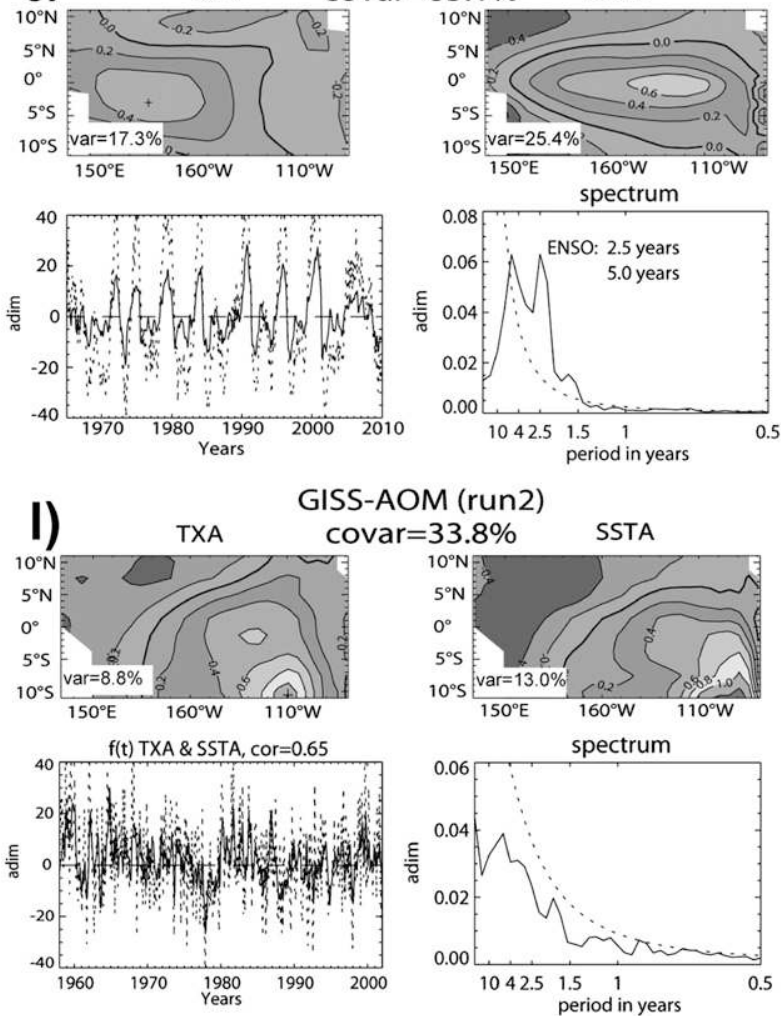

\section{$M$ (run2)}
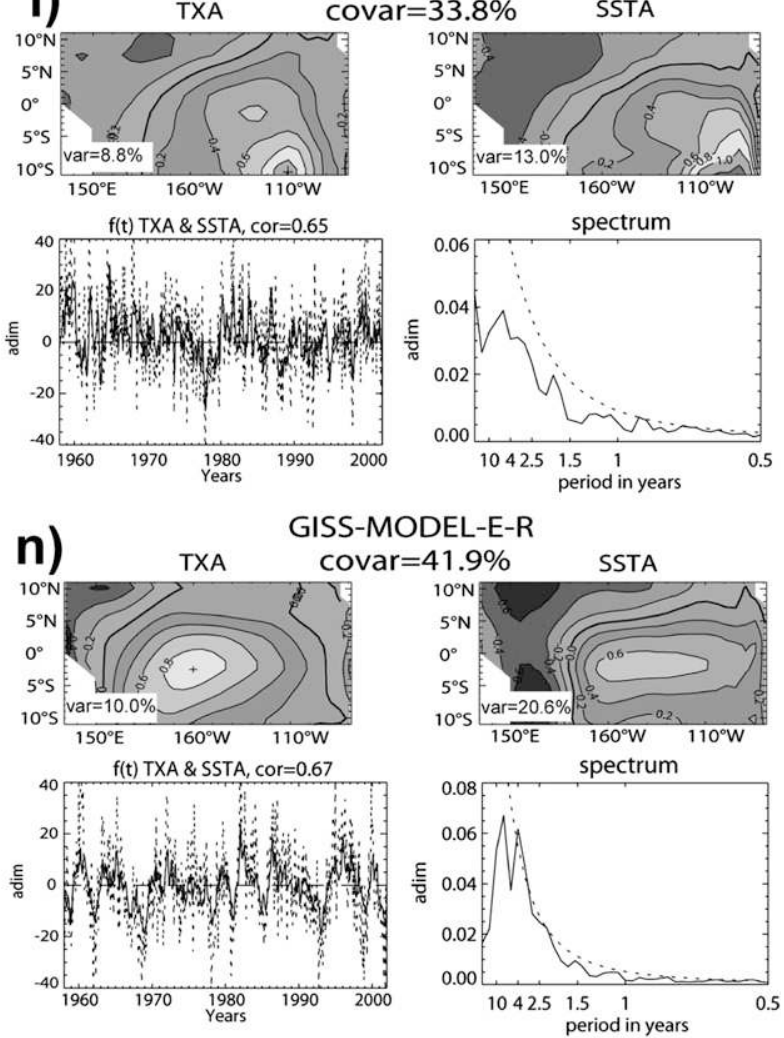

FIG. 1. (Continued) 
NGV-ECHAM4

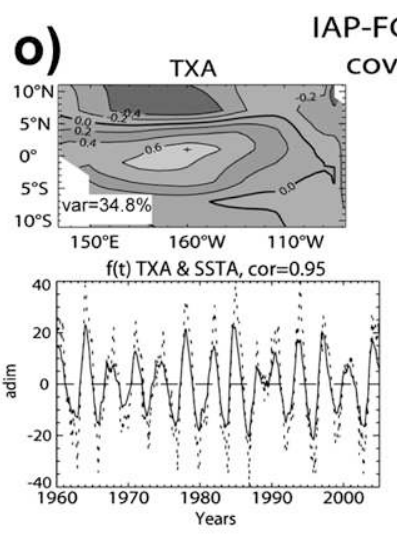

covar $=97.5 \% \quad$ SSTA
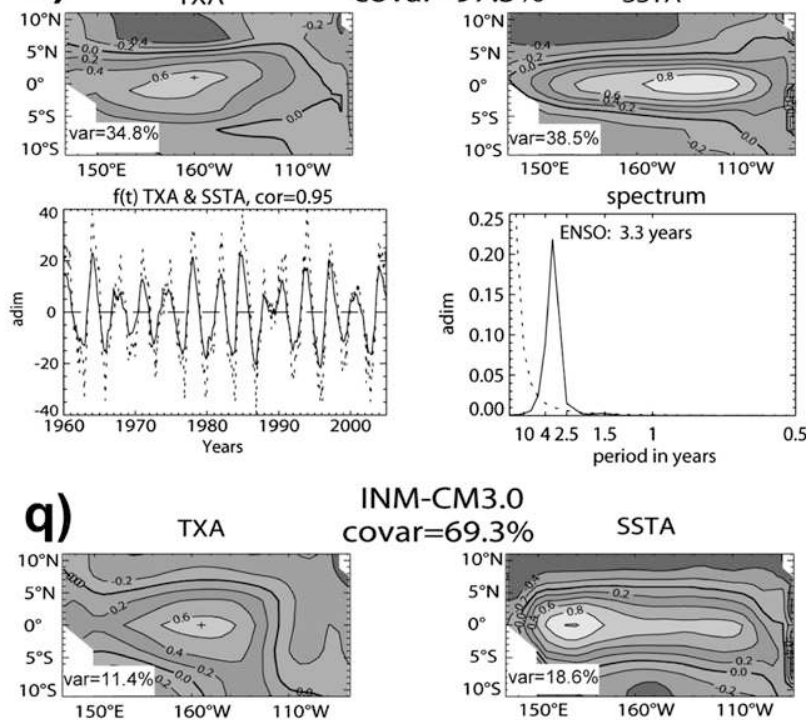

INM-CM3.0

covar $=69.3 \% \quad$ SSTA
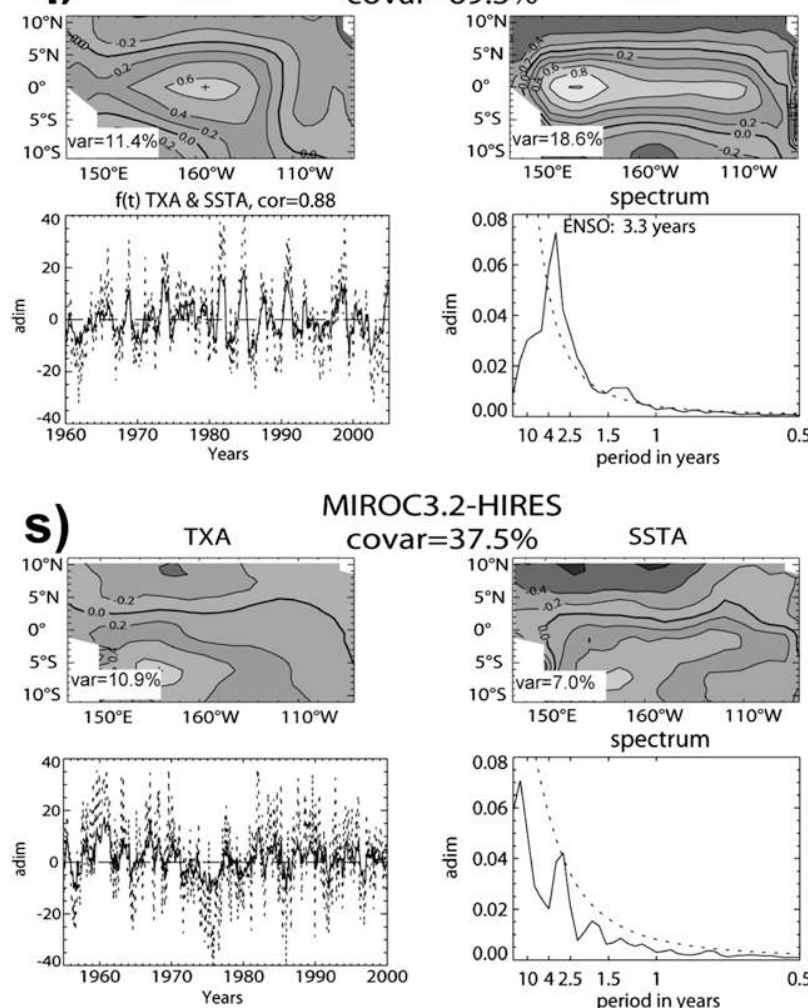
covar $=37.5 \%$
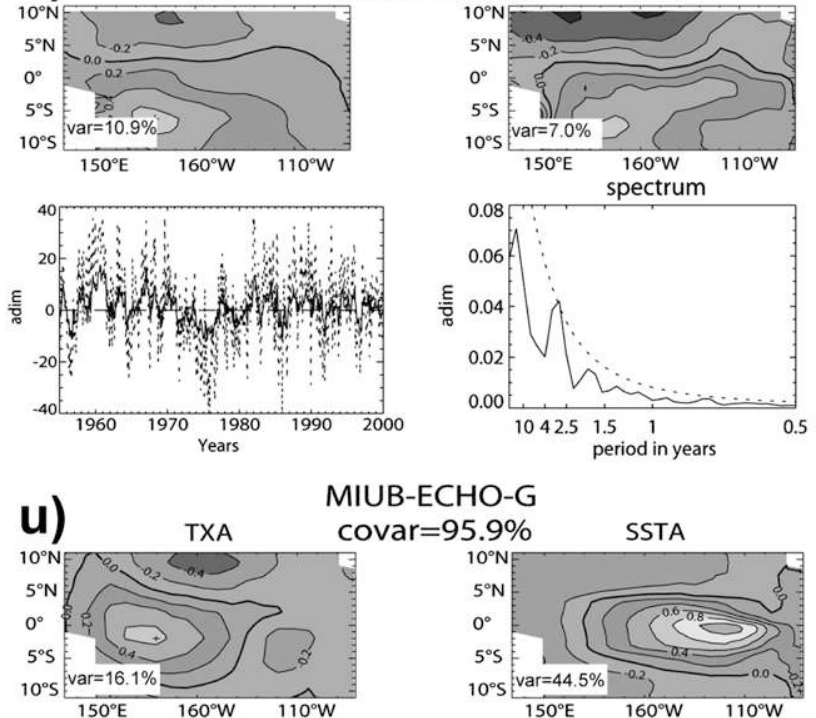

MIUB-ECHO-G covar $=95.9 \%$
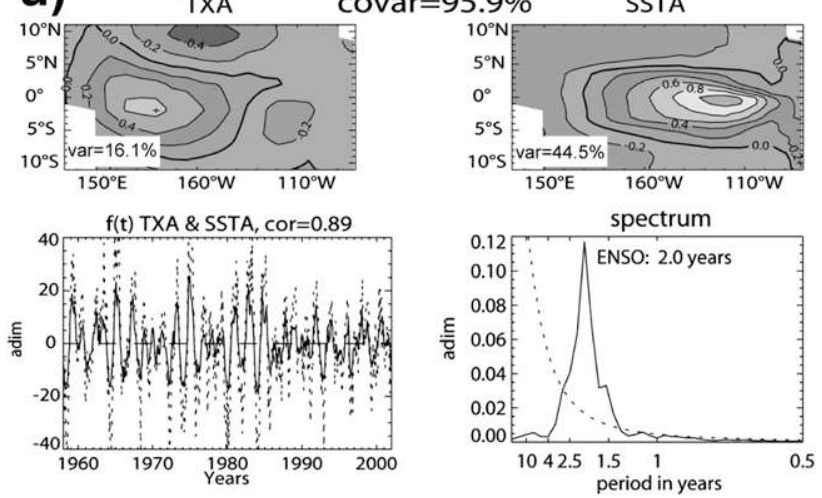
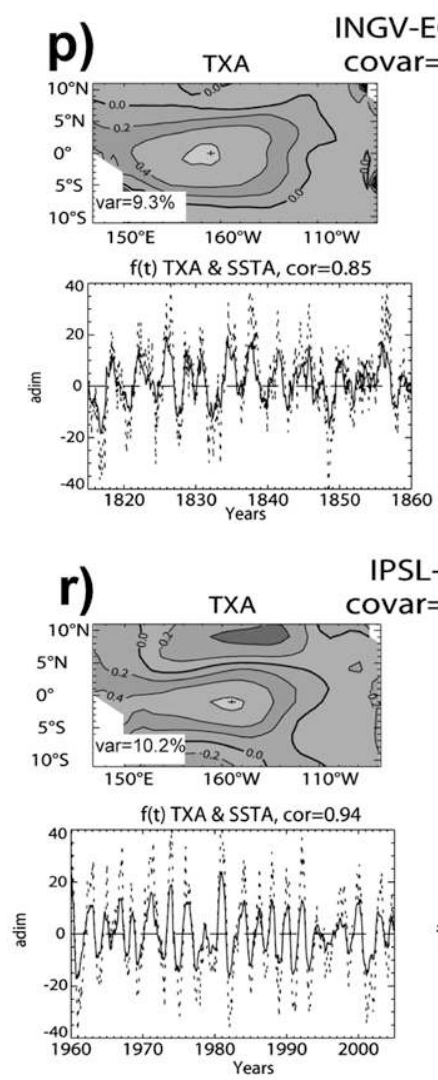

IPSL-CM4
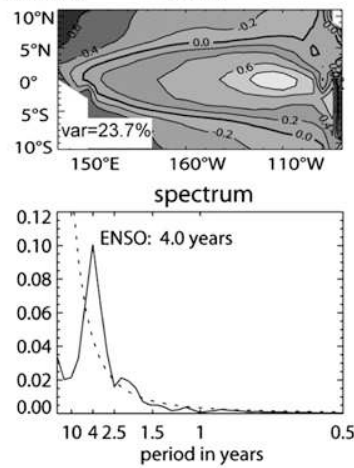

covar $=93.0 \% \quad$ SSTA
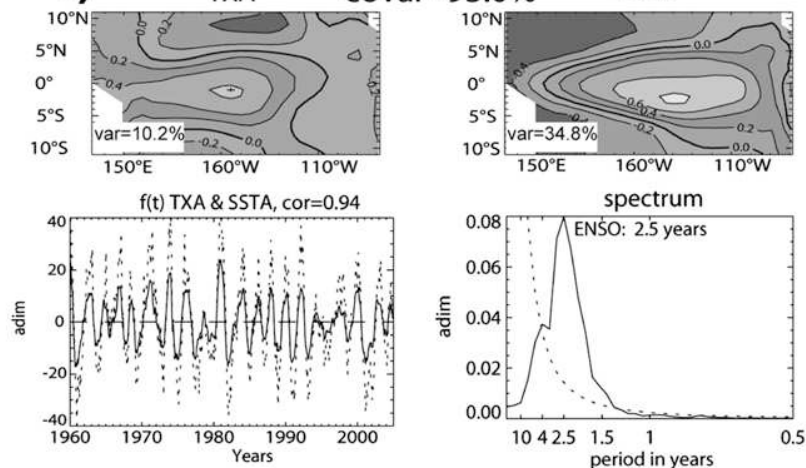
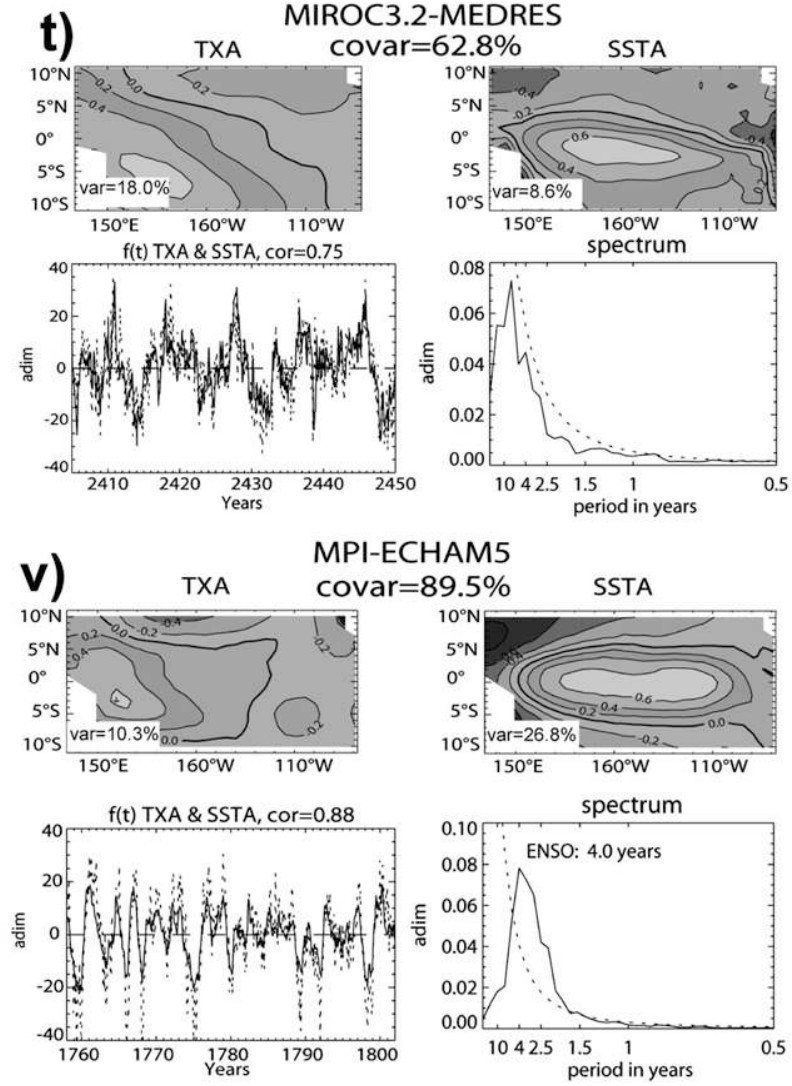

FIG. 1. (Continued) 

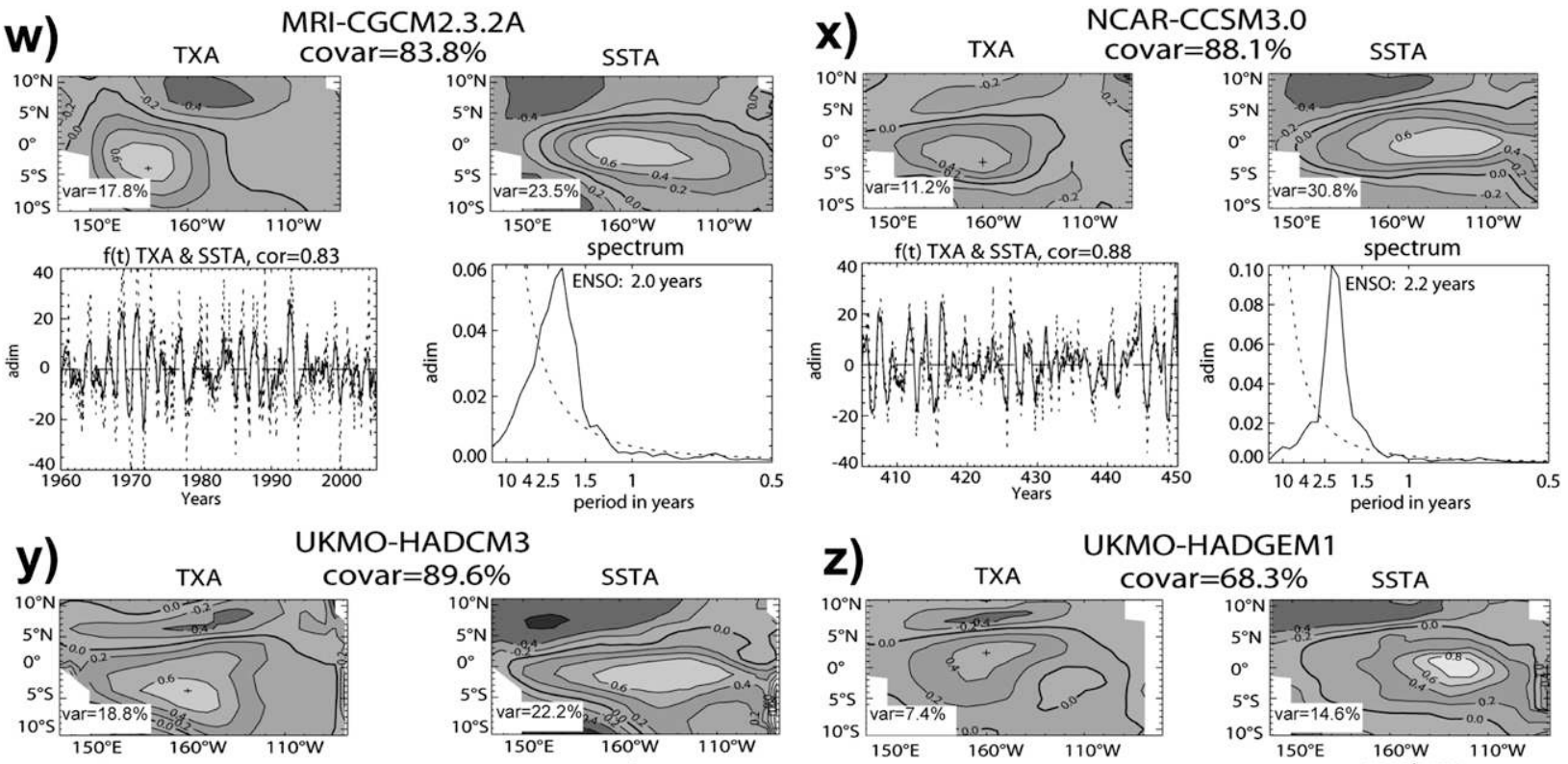

KMO-HADCM3
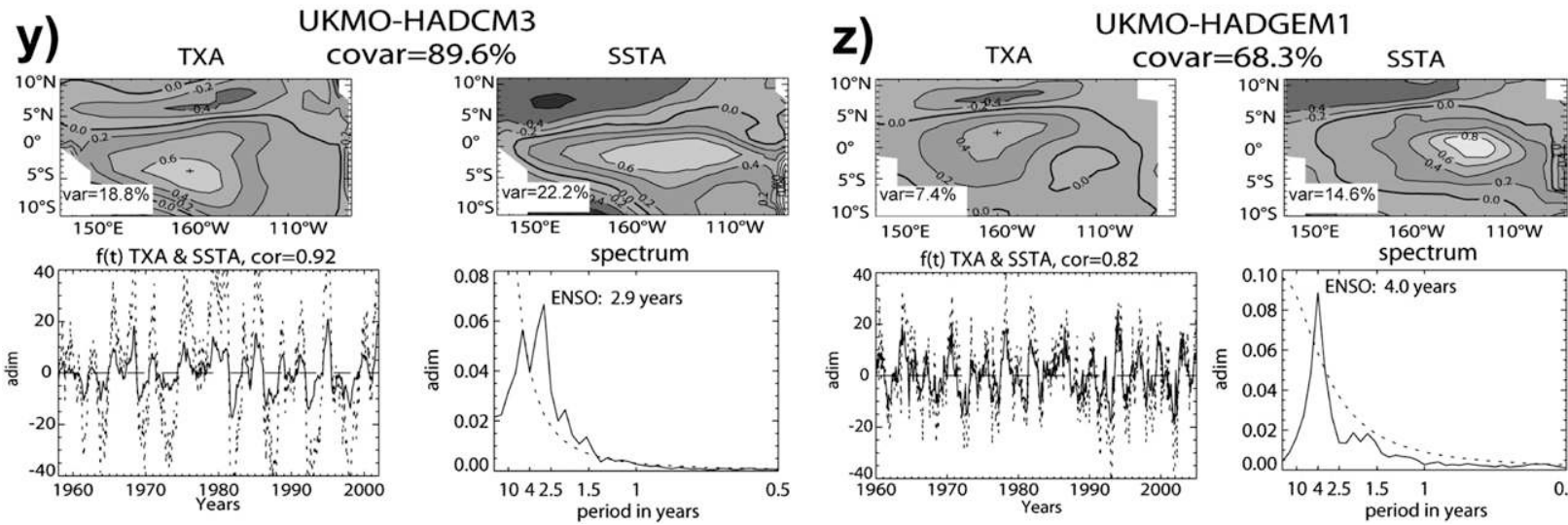

FIG. 1. (Continued)

the SVD analysis tends to capture some "slower" variability modes.

Results of the SVD are presented for the multimodel ensemble in Fig. 1, and the estimated ENSO periods are listed in Table 2. Consistently with previous analyses (VPC05; Capotondi et al. 2006; G06), though most CGCMs are able to capture ENSO-like interannual variability, they show a great diversity of spatial patterns for both wind stress and SST anomalies, together with a wide range of dominant ENSO frequencies: from $2.0 \mathrm{yr}$ [Commonwealth Scientific and Industrial Research Organisation Mark version 3.0 (CSIRO Mk3.0), Meteorological Institute of the University of Bonn (MIUB) ECHAM and the global Hamburg Ocean Primitive Equation (ECHO-G) Model (MIUBECHOG), and Meteorological Research Institute (MRI) Coupled General Circulation

TABLE 2. ENSO periods of the models. The CGCMs listed in boldface are those considered in the rest of the paper (after this section).

\begin{tabular}{lclc}
\hline \multicolumn{1}{c}{ Model name } & ENSO period (yr) & \multicolumn{1}{c}{ Model name } & ENSO period (yr) \\
\hline SODA 1.4.2 & 3.7 & GISS-ER & - \\
GODAS & 5.0 & IAP FGOALS-g1.0 (run 1) & 3.3 \\
BCCR-BCM2.0 & 4.0 & INGV ECHAM4 & 4.0 \\
CCCma CGCM3.1 & - & INM-CM3.0 & 3.3 \\
CCCma CGCM3.1 (T63) & - & IPSL CM4 & 2.5 \\
CNRM-CM3 & 3.3 & MIROC3.2(hires) & - \\
CSIRO Mk3.0 (run 1) & 2.0 & MIROC3.2(medres) & - \\
CSIRO Mk3.5 & 5.0 & MIUBECHOG & 2.0 \\
GFDL CM2.0 & 3.3 & MPI ECHAM5 & 4.0 \\
GFDL CM2.1 & $5.0 / 2.5$ & MRI CGCM2.3.2a & 2.0 \\
GISS-AOM (run 1) & - & NCAR CCSM3.0 (run 2) & 2.2 \\
GISS-AOM (run 2) & - & UKMO HadCM3 (run 1) & 2.9 \\
GISS-EH & - & UKMO HadGEM1 & 4.0 \\
\hline
\end{tabular}


Model, version 2.3.2a (MRI CGCM2.3.2a)] to $5.0 \mathrm{yr}$ (CSIRO Mk3.5 and GFDL CM2.1), SODA showing a typical ENSO period of $3.7 \mathrm{yr}$.

To check the validity of the ENSO period estimate provided by the SVD analysis computed with SODA, the spectrum of Niño-3 SST anomalies was computed from the ERSST dataset (not shown). With a 15-yr running window, the ENSO periods over both the 44-yr SODA period (1958-2001) and the 129-yr ERSST period (1880-2008) are equal to the value obtained from the SVD performed with SODA: 3.7 yr. Note, however, that with a 20-yr window (like for the CGCMs) over the entire period covered by ERSST, ENSO is characterized by a 3.3-yr period. These results validate to a large extent the SVD approach and the choice of SODA to estimate the observed length of the ENSO cycle. However, they raise the issue of the width of the moving window and hence the issue of the limited time periods spanned by the reanalyses. Caution is thus needed here for interpreting the modeled ENSO time scales in case of small differences with SODA (approximately 0.3$0.4 \mathrm{yr}$ ). Note that GODAS, which considers the period after the 1976 climate shift known to be characterized with lower ENSO frequency (Moon et al. 2004), exhibits a longer time scale.

Spectrums exhibit a variety of shapes, from a narrow band centered around the main peak of interannual variability [e.g., Centre National de Recherches Météorologiques Coupled Global Climate Model, version 3 (CNRM-CM3); MIUBECHOG] to a wide spectrum with several peaks [e.g., CSIRO Mk3.0; the third climate configuration of the Met Office Unified Model (UKMO HadCM3)]. Note that two dominant peaks of similar magnitude were found for GFDL CM2.1 at 2.5 and $5.0 \mathrm{yr}$ (Table 2), whatever the chosen length for the running window. We chose to retain the lower-frequency peak for the estimate of the ENSO period, in order to extract a longer ENSO cycle than for GFDL CM2.0 (3.3 yr), consistently with the spectral analysis of the Niño-3 index performed by Wittenberg et al. (2006).

Seven models do not exhibit any significant peak in the interannual frequency band: the Canadian Centre for Climate Modelling and Analysis (CCCma) Coupled General Circulation Model, version 3.1 (CGCM3.1) (T47); CCCma CGCM3.1 (T63); Goddard Institute for Space Studies (GISS) Atmosphere-Ocean Model (GISSAOM) (run 1 and 2); GISS Model E-H (GISS-EH); GISS Model E-R (GISS-ER); Model for Interdisciplinary Research on Climate 3.2, high-resolution version [MIROC3.2(hires)]; MIROC 3.2, medium-resolution version [MIROC3.2(medres)]. Among them, five models [CCCma CGCM3.1 (T63), GISS-AOM, GISS-ER, MIROC3.2(hires), and MIROC3.2(medres)] simulate unrealistic characteristics of the dominant mode of tropical variability: in particular, the covariances explained by the first SVD mode are considerably lower [respectively, $54 \%, 34 \%, 34 \%, 42 \%, 38 \%$, and $63 \%$ for CCCma CGCM3.1 (T63), GISS-AOM run 1, GISS-AOM run 2, GISS-ER, MIROC3.2(hires), and MIROC3.2(medres) models] than that for SODA (86\%) and GODAS (83\%). In addition, the associated SST anomaly patterns exhibit displaced and under- or overestimated maxima for these models in comparison with SODA (Fig. 1). Consequently, these seven CGCMs will not be taken into account in the rest of the study. Note that most of these models are also not considered in the analyses of the studies by VPC05 and G06 because of the absent (GISS-AOM, GISS-ER) or weak [CCCma CGCM3.1 (T47), GISS-EH, MIROC3.2(hires), and MIROC3.2(medres)] ENSO variability. In the following, for clarity, only the 16 CGCMs listed in boldface in Table 2 will be considered in the rest of the paper.

\section{2) DiAgNosing THE PRIVILEGED DYNAMICAL REGIME}

Rather than using a statistical approach to determine the privileged ENSO regime for the CGCMs, we make use of a simple dynamical model of the tropical Pacific with prescribed wind forcing and a linearization of the ocean dynamics around a mean oceanic state derived from the CGCMs. Such procedure has two main advantages: 1) despite the simplified formulation of the embedded mixed layer model (see below), it allows deriving explicitly the actual contribution of the tendency terms of the SST equation (including nonlinear advection), which would require the manipulation of large datasets (tridimensional temperature and velocity fields) if based solely on the direct CGCM outputs; 2) it makes it possible to get a direct estimation of upwelling from the CGCMs (which remains difficult to obtain from the direct model outputs), which can be compared to an estimate from a different wind product.

The linear model is the oceanic component of an intermediate coupled model (ICM) named the Linear Ocean Dynamically Coupled to Atmosphere (LODCA) and described by Dewitte (2000). For clarity we will simply refer to the linear model as LODCA. It can be viewed as an extension of the oceanic component of the $\mathrm{CZ}$ model in the context of several baroclinic modes instead of one. The model solves an infinite number of horizontal modes for each baroclinic mode. The circulation is driven by adiabatic, linear shallow-water wave dynamics. It includes three baroclinic modes with characteristics of phase speed $c_{n}$, wind projection coefficient (Lighthill 1969) 


$$
P_{n}=\frac{H_{\mathrm{th}}}{\int_{-H_{\text {mix }}}^{0} F_{n}^{2}(z) d z},
$$

friction $r_{n}$, and thermocline coefficient

$$
\operatorname{scl}_{n}(z)=\frac{g}{N^{2}(z)} \frac{d F_{n}}{d z}(z)
$$

where $N^{2}$ is the Brünt-Väisälä frequency, $F_{n}$ are the solutions of the eigenvalue problem with the appropriate boundary conditions (Fjeldstad 1933), $H_{\text {mix }}=50 \mathrm{~m}$ and $H_{\text {th }}=150 \mathrm{~m}$ are the zonally uniform constant mixed layer depth and an adimensionalizing coefficient (corresponding roughly to the observed mean thermocline depth in the central Pacific), respectively. The $P_{n}$ quantifies the amount of momentum flux that projects on a particular baroclinic mode. In that sense they characterize the thermocline structure and bring information on how the ocean has to respond (in the linear sense) to wind stress forcing. The geostrophic currents are computed from the contributions of the three baroclinic modes, and upwelling is inferred from the divergence of the mixed layer currents. The $\operatorname{scl}_{n}$ weight the different sea level baroclinic contributions to thermocline displacements-see Dewitte (2000) for details.

Values for these parameters are prescribed to those obtained from the results of a vertical mode decomposition of the mean equatorial stratification performed for each of the IPCC models. The density profile used for the decomposition is taken at the location (along the equator) of the maximum variability of the zonal wind stress anomaly pattern associated with the first SVD mode between SST and wind stress anomalies (see above). This choice was motivated by the fact that this is where the impact of the wind forcing on the ocean dynamics is the strongest at interannual time scales. The procedure allows fitting the mean stratification and vertical structure of LODCA to that of each of the CGCMs.

As in Zebiak and Cane (1987), SST anomalies are computed from a fully nonlinear surface mixed layer temperature equation that considers mostly large-scale zonal and vertical advections (Dewitte 2000):

$$
\begin{aligned}
\frac{\partial T^{\prime}}{\partial t}= & -u^{\prime}\left(\bar{T}+T^{\prime}\right)_{x}-\bar{u}\left(T^{\prime}\right)_{x}-v^{\prime}\left(\bar{T}+T^{\prime}\right)_{y}-\bar{v}\left(T^{\prime}\right)_{y} \\
& -\gamma\left[M\left(\bar{w}+w^{\prime}\right)-M(\bar{w})\right] \bar{T}_{z}-\gamma M\left(\bar{w}+w^{\prime}\right) \frac{T^{\prime}-T_{\mathrm{sub}}^{\prime}\left(h^{\prime}, \bar{h}\right)}{H_{\text {mix }}}-\alpha T^{\prime}
\end{aligned}
$$

$[M(x)$ is a step function: $M(x)=x$ if $x \geq 0 ; M(x)=0$ if $x<0]$.

The quantities $T^{\prime},\left(u^{\prime}, v^{\prime}, w^{\prime}\right)$, and $h^{\prime}$ stand for the anomalies for SST, surface velocity field (vertical velocities are at the base of the mixed layer), and thermocline displacements, respectively. Quantities with overbars represent climatological fields and the prime marks represent anomalies relative to the seasonal cycle; $T_{\text {sub }}$ represents subsurface temperature at the base of the mixed layer and is parameterized as in Dewitte and Périgaud (1996); $x, y$, and $z$ indices stand for the partial derivatives according to the respective spatial coordinates; $\gamma$ is the efficiency factor relating entrainment to upwelling-it varies from west to east between the values of 0.5 and 1.0 in order to take the effect of a zonally varying mixed layer depth into account (see Dewitte 2000); $\alpha$ is a damping coefficient equal to $(115 \text { days })^{-1}$. The term $-u^{\prime}\left(\bar{T}+T^{\prime}\right)_{x}$ is for zonal advection of temperature by the zonal current anomalies. It comprises both anomalous advection of mean temperature $-u^{\prime}(\bar{T})_{x}$ and nonlinear zonal advection $-u^{\prime}\left(T^{\prime}\right)_{x}$ terms. The $-\bar{u}\left(T^{\prime}\right)_{x}$ is for zonal advection of temperature anomalies by the mean zonal currents. The $-v^{\prime}\left(\bar{T}+T^{\prime}\right)_{y}$ and $-\bar{v}\left(T^{\prime}\right)_{y}$ are for the meridional counterparts. The $-\gamma\left[M\left(\bar{w}+w^{\prime}\right)-M(\bar{w})\right] \bar{T}_{z}$ represents vertical entrainment of mean temperature across the thermocline by the vertical current anomalies and is only for upwelling. And $-\gamma M\left(\bar{w}+w^{\prime}\right)\left[T^{\prime}-T_{\text {sub }}^{\prime}\left(h^{\prime}, \bar{h}\right) / H_{\text {mix }}\right]$ is for vertical entrainment of temperature anomalies across the thermocline by the total upwelling. It comprises both vertical advection of temperature anomalies by the mean currents $-\gamma \bar{w}\left[T^{\prime}-T^{\prime}\left(h^{\prime}, \bar{h}\right) / H_{\text {mix }}\right]$ and nonlinear vertical advection $-\gamma w^{\prime}\left[T^{\prime}-T_{\text {sub }}^{\prime}\left(h^{\prime}, \bar{h}\right) / H_{\text {mix }}\right]$ terms. For simplicity, $-\gamma\left[M\left(\bar{w}+w^{\prime}\right)-M(\bar{w})\right] \bar{T}_{z}$ and $-\gamma M\left(\bar{w}+w^{\prime}\right)$ $\left[T^{\prime}-T_{\text {sub }}^{\prime}\left(h^{\prime}, \bar{h}\right) / H_{\text {mix }}\right]$ will be respectively refered to as $-w^{\prime}(\bar{T})_{z}$ and $-w\left(T^{\prime}\right)_{z}$ in the rest of the paper. The term $-\alpha T^{\prime}$ is a Newtonian damping term and includes the contribution of surface heat flux anomalies.

LODCA is similar to the CZ model, except it takes the vertical structure explicitly into account with three baroclinic modes and uses a different parameterization of subsurface temperature (Dewitte and Périgaud 1996; Dewitte 2000). The main advantage in comparison to a model using only one baroclinic mode (e.g., the $\mathrm{CZ}$ model) is that sea level and zonal current anomalies are more realistic with more than one vertical mode (Dewitte et al. 1999; 2002). This is because wave dissipation is not solely 
taken into account through a Rayleigh-type friction but also through vertical propagation of energy (Dewitte and Reverdin 2000). Hence we expect to better represent with LODCA the contribution of the tendency terms of the SST equation and derive a more robust estimate of the dominant feedbacks in the CGCMs than with a model using one baroclinic mode.

More generally, the other interesting aspects of the approach with LODCA are 1) to provide a method for comparing models having different characteristics (resolution and mixing scheme among others);2) to evaluate for each CGCM to what degree its tropical variability can be considered a "linear" response to the wind forcing.

The linear model is forced with wind stress as derived from the IPCC models in order to fit its dynamics to those of the CGCMs with a focus on the equatorial waveguide. A preliminary step consists of deriving the climatological velocity and SST fields from the CGCMs in order to prescribe them in LODCA. This allows a complete fit of the mean state to that of the CGCMs to be achieved. For the velocity field, this is achieved by forcing LODCA with the climatological wind stress from the CGCMs. The climatology for SST is directly inferred from the CGCMs' outputs. In a second step, LODCA-in which these climatologies are prescribed-is forced with the wind stress anomalies so as to derive SST anomalies and the tendency terms of the SST equation. Similar methodology was used in Dewitte et al. (2007a,b).

The simulated SST anomalies from LODCA are compared to the direct CGCM outputs. The results of the comparison are provided in Table 3 for the Niño-3 SST index, which shows a good agreement between LODCA and the CGCMs: the correlation is above $75 \%$ for all the models. The discrepancies between the LODCA SSTs and the CGCM SSTs may be due to a number of processes: these include the nonlinearities present in the CGCMs but not in LODCA (the latter only accounts for nonlinear advection associated with long wavelength equatorial waves), the reflections of the equatorial waves (LODCA having an idealized coastline with no throughflow), the dispersion and dissipation processes associated with thermocline variability (LODCA having a steady homogeneous thermocline for the baroclinic component), or the surface heat fluxes (which are very simply parameterized in LODCA). Nonetheless, results of Table 3 indicate that the variability of most models can be accounted for to a large extent by linear dynamics.

A simple theoretical framework is then used to provide a diagnostic of the privileged dynamical regime in the IPCC models, based on the estimation of the tendency terms of the SST equation. The inspection of the variability of these various tendency terms provides pieces of information on the relative importance of the thermocline
TABLE 3. Comparison between CGCM and LODCA outputs.

\begin{tabular}{lcc}
\hline & Niño-3 SST (LODCA and CGCM) \\
\cline { 2 - 3 } \multicolumn{1}{c}{ Model name } & Correlation & $\begin{array}{c}\text { RMS } \\
\text { difference }\left({ }^{\circ} \mathrm{C}\right)\end{array}$ \\
\hline SODA 1.4.2 & 0.85 & 0.76 \\
GODAS & 0.78 & 0.64 \\
BCCR-BCM2.0 & 0.89 & 0.57 \\
CNRM-CM3 & 0.96 & 0.84 \\
CSIRO Mk3.0 (run 1) & 0.86 & 0.57 \\
CSIRO Mk3.5 & 0.89 & 0.40 \\
GFDL CM2.0 & 0.87 & 0.44 \\
GFDL CM2.1 & 0.85 & 0.78 \\
IAP FGOALS-g1.0 (run 1) & 0.96 & 0.57 \\
INGV ECHAM4 & 0.94 & 0.34 \\
INM-CM3.0 & 0.90 & 0.51 \\
IPSL CM4 & 0.94 & 0.41 \\
MIUBECHOG & 0.89 & 0.62 \\
MPI ECHAM5 & 0.77 & 0.78 \\
MRI CGCM2.3.2a & 0.82 & 0.48 \\
NCAR CCSM3.0 (run 2) & 0.90 & 0.40 \\
UKMO HadCM3 (run 1) & 0.93 & 0.58 \\
UKMO HadGEM1 & 0.86 & 0.42 \\
\hline
\end{tabular}

(vertical advection) and zonal advective (zonal advection) feedbacks. Note that in the conceptual model of Jin and An (1999), only anomalous zonal advection of mean temperature $\left[-u^{\prime}(\bar{T})_{x}\right]$ and mean vertical advection of anomalous temperature $\left[-\bar{w}\left(T^{\prime}\right)_{z}\right]$ are considered to analyze the relative importance of the thermocline and zonal advective feedbacks. In theory, all terms should be taken into account. Here, all the advection terms are considered in the analysis: it reveals that the deviations (from the real world) in the balance between the two feedbacks are best accounted for by the mean vertical advection of anomalous temperature $\left[-\bar{w}\left(T^{\prime}\right)_{z}\right]$ and the mean zonal advection of anomalous temperature $\left[-\bar{u}\left(T^{\prime}\right)_{x}\right]$, as will be seen below. Note that this does not mean that $-u^{\prime}(\bar{T})_{x}$ is not a significant contributor to the SST changes. However, this term does not account for the main differences between models (see below).

In the following section, results based on the LODCA simulations are used to classify the models in groups relevant for their main ENSO dynamical regime.

\section{ENSO regime and mean state}

\section{a. SST tendency terms: Variability and biases}

In the rest of the study, it is assumed that for most CGCMs, biases in ENSO variability can be accounted for by the over or underestimation of the zonal advective feedback and/or the thermocline feedback. This means that the role of the wind response to SST anomalies, the damping, and the atmospheric noise properties are not investigated here, in spite of their importance for the 

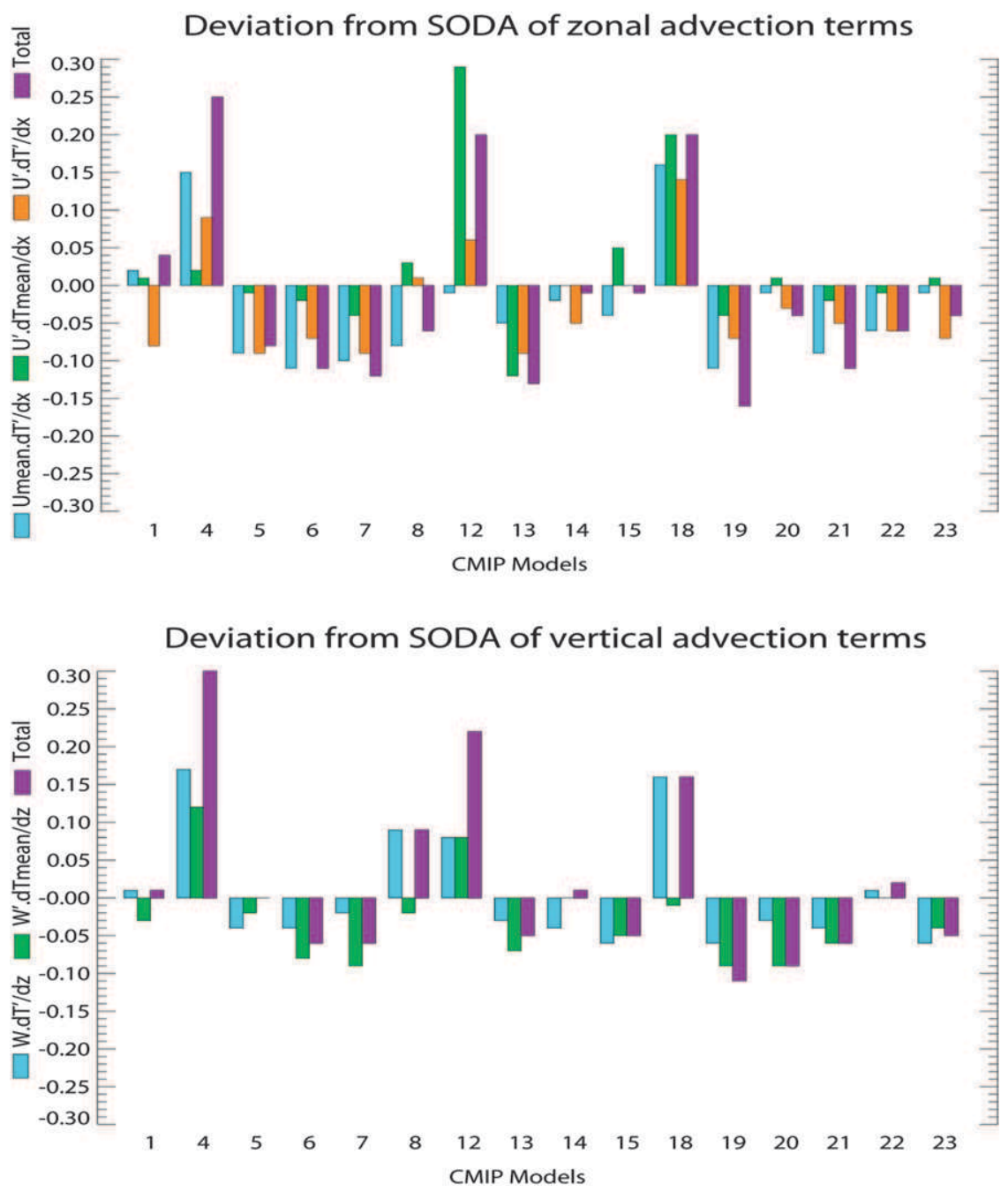

FIG. 2. Histogram of the deviation in the variability of the advection terms (referenced to SODA) for the CMIP3 models: (top) zonal advection terms averaged in the Niño-4eq region and (bottom) vertical advection terms averaged in the Niño-3eq region. Model names are referenced in Table 1 . Units are ${ }^{\circ} \mathrm{C}$ month ${ }^{-1}$.

ENSO cycle (e.g., VPC05; Philip and van Oldenborgh 2009, 2010). Note, however, that according to the same studies, the dominant contributors to the SST changes associated with ENSO are the zonal advective and thermocline feedbacks: although the present study does not explicitly consider the dominant role of the atmospheric component in the simulated ENSO, its effect on SST is implicitly taken into account in the heat budget analysis performed with the linear model.

The variability of the tendency terms (as derived from the LODCA simulations performed with each CGCM) is assumed to provide estimates of the strength of zonal-vertical advection processes. Deviations from the results obtained with LODCA fitted to the SODA reanalysis are thus expected to reflect the tendency of the CGCMs toward one feedback regime or the other. A classification of the CGCMs in terms of the dominant feedback process is therefore proposed. It is based on the departures in the variability of the zonal and vertical advection terms respectively in the westerncentral Pacific and the eastern Pacific, as detailed in the following.

Figure 2 presents the deviation of the variability (RMS) of the zonal and vertical advection terms relatively to SODA, obtained from the 16 studied CGCMs. For simplicity, we will refer as "departure" the deviation from SODA hereafter, unless specified. A detailed examination of Fig. 2 allows quantifying which tendency terms account the most for the departures in total zonal-vertical advection. For instance, the top panel of Fig. 2 indicates 
TABLE 4. Number of CGCMs with departures in tendency terms with the same sign and order of magnitude of the departure for total zonal-vertical advection.

\begin{tabular}{|c|c|c|c|c|c|c|}
\hline & \multicolumn{3}{|c|}{ Same sign } & \multicolumn{3}{|c|}{ Same order of magnitude } \\
\hline & SODA & GODAS & Ensemble mean & SODA & GODAS & Ensemble mean \\
\hline$-\bar{u}\left(T^{\prime}\right)_{x}$ & 15 & 12 & 13 & 10 & 6 & 11 \\
\hline$-u^{\prime}(\bar{T})_{x}^{x}$ & 11 & 14 & 12 & 3 & 7 & 8 \\
\hline$-u^{\prime}\left(T^{\prime}\right)_{x}$ & 13 & 10 & 13 & 7 & 5 & 5 \\
\hline$-w\left(T^{\prime}\right)_{z}$ & 14 & 7 & 15 & 11 & 6 & 10 \\
\hline$-w^{\prime}(\bar{T})_{z}$ & 10 & 12 & 14 & 9 & 3 & 6 \\
\hline
\end{tabular}

that mean zonal advection of anomalous temperature $\left[-\bar{u}\left(T^{\prime}\right)_{x}\right.$; light blue bars] can be significantly larger or smaller in the IPCC models than in SODA, with a tendency to have a deviation from SODA comparable to that of total zonal advection (purple bars). Similarly, the bottom panel of Fig. 2 reveals that the departure in mean vertical advection of anomalous temperature is comparable to the departure in total vertical advection, except for two models [namely, CSIRO Mk3.0 and Institute of Numerical Mathematics Coupled Model, version 3.0 (INM-CM3.0)].

To quantify such observations, Table 4 presents for each tendency term the number of models that have a departure (relatively to different references) of the same sign/order of magnitude ( $\pm 50 \%$ of the value) as that of the sum of the zonal-vertical advection terms. It reveals that, whatever the reference, zonal-vertical advection by the mean currents are the most representative terms to account for the departures in total zonal-vertical advection. These terms can thus be considered "proxies" of the departures of the CGCMs with respect to the strength of the zonal advective-thermocline feedback. Results relative to GODAS are a bit less conclusive. This may be due to the shorter period spanned by GODAS as will be discussed later on.

\section{b. Model classification}

To assess the relative importance of the zonal advective feedback and the thermocline feedback in the CGCMs, the variability of $-w\left(T^{\prime}\right) z$ [averaged in the Niño-3eq region $\left.\left(0^{\circ}, 150^{\circ}-90^{\circ} \mathrm{W}\right)\right]$ as a function of the variability of $-\bar{u}\left(T^{\prime}\right)_{x}$ [averaged in the Niño-4eq region $\left(0^{\circ}, 160^{\circ} \mathrm{E}-\right.$ $150^{\circ} \mathrm{W}$ )] is presented in Fig. 3 (top panel). Interestingly, Fig. 3 indicates that there is no clear linear relationship between the two advection terms among all the models. This illustrates the diversity in behaviors of the CGCMs of the IPCC in terms of the privileged dynamical regime. The CGCMs are gathered around GODAS and the ensemble mean, with models having a tendency to overestimate mean zonal advection (circle group) and others mean vertical advection (square group). In between, there is a group (stars) of models that exhibit a balance between advection terms comparable to both GODAS and the ensemble mean. SODA also belongs to this category, though it has larger zonal advection than the other references.

To assess to what extent the ratio between $-w\left(T^{\prime}\right)_{z}$ and $-\bar{u}\left(T^{\prime}\right)_{x}$ is controlled by the mean state (and more specifically by the mean circulation characteristics), we first suppose a linear behavior of vertical currents around the mean upwelling. By doing this, we assume that perturbations in the eastern Pacific are weak in comparison to the mean vertical flow so that $w\left(T^{\prime}\right)_{z} \approx \bar{w}\left(T^{\prime}\right)_{z}$. The vertical gradient of temperature anomalies $\left(T^{\prime}\right)_{z}$ in the eastern Pacific depends on the SST anomalies but also on the anomalies of subsurface temperature $T_{\text {sub }}^{\prime}$, itself depending on the displacements of the thermocline. As a first approximation, this quantity varies linearly with anomalous thermocline displacements, so we infer that $w\left(T^{\prime}\right)_{z} \approx \bar{w}\left[\left(T^{\prime}-a h^{\prime}\right) / H_{\text {mix }}\right]$, where $a=\partial T_{\text {sub }} / \partial h$ is a constant quantity. Here $T^{\prime}$ is for SST anomalies in the Niño-3 region $\left(5^{\circ} \mathrm{S}-5^{\circ} \mathrm{N}, 150^{\circ}-90^{\circ} \mathrm{W}\right)$. The Niño-3.4 region $\left(5^{\circ} \mathrm{S}-5^{\circ} \mathrm{N}, 170^{\circ}-120^{\circ} \mathrm{W}\right)$ may also be used here to some extent (see below).

On the other hand, when averaged over the centralwestern Pacific, the zonal gradient of temperature anomalies $\left(T^{\prime}\right)_{x}$ is mainly controlled by SST anomalies east of the date line: indeed, the anomalies are generally much weaker over the warm pool, and their typical zonal scale L does not vary much among the models, which tend to have an overestimated westward extension (Fig. 1). Hence $\bar{u}\left(T^{\prime}\right)_{x} \propto \bar{u}\left(T^{\prime} / L\right)$ in most cases. Here $T^{\prime}$ is for SST anomalies in the central Pacific, roughly in the Niño-3.4 region.

Consequently, a simplified SST equation that accounts for the biases of the zonal-vertical advection terms can be written as follows:

$$
\frac{\partial T^{\prime}}{\partial t}=-\left[\left(\frac{\bar{u}}{L}+\frac{\bar{w}}{H_{\text {mix }}}\right) T^{\prime}-\frac{a \bar{w}}{H_{\text {mix }}} h^{\prime}\right],
$$

where $T^{\prime}\left(h^{\prime}\right)$ is for SST (thermocline) anomalies in the Niño-3.4 region.

The differences among the models are significantly higher for $\bar{u}$ than for $\bar{w}$ as will be seen below (Fig. 3, bottom panel), so we can consider as a first approximation that 
Main Advection Terms in the CMIP

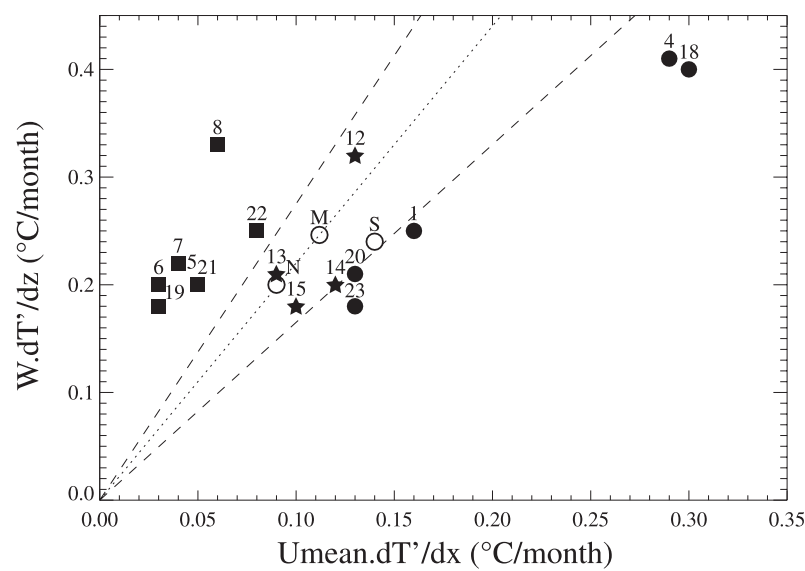

Umean and Wmean in the CMIP

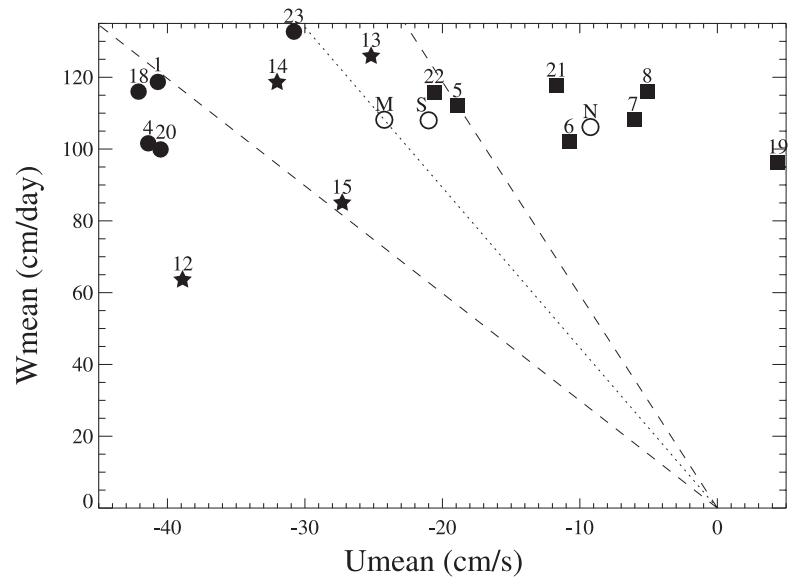

FIG. 3. (top) Scatterplot of the RMS of vertical advection of anomalous temperature by the total equatorial vertical currents $-w\left(T^{\prime}\right)_{z}$ vs the RMS of zonal advection of anomalous temperature by the equatorial mean zonal currents $-\bar{u}\left(T^{\prime}\right)_{x}$ for the CMIP3 models. The $-w\left(T^{\prime}\right)_{z}\left[-\bar{u}\left(T^{\prime}\right)_{x}\right]$ is averaged in the Niño-3eq (Niño4eq) region. The dotted line represents the straight line having a slope corresponding to the multimodel ensemble mean [i.e., mean value of $\left.w\left(T^{\prime}\right)_{z} / \bar{u}\left(T^{\prime}\right)_{x}\right]$, and the dashed lines have slopes corresponding to $125 \%$ and $75 \%$ of the slope of the dotted line. Model symbols correspond to their positions relative to the dashed lines: stars between them, filled circles on their right-hand side, and squares on their left-hand side. Unfilled circles are for the references: S stands for SODA, N stands for GODAS, and M stands for the multimodel ensemble mean. Model names are referenced in Table 1. Note that CSIRO Mk3.0 and NCAR CCSM3.0 have the same position. Units are ${ }^{\circ} \mathrm{C}$ month ${ }^{-1}$. (bottom) Scatterplot of the mean vertical velocities $\bar{w}$ (averaged over Niño-3eq) vs the mean surface zonal velocities $\bar{u}$ (averaged over Niño-4eq) for the CMIP3 models. The dotted line has a slope corresponding to the multimodel ensemble mean and the dashed lines have slopes corresponding to $67 \%$ and $133 \%$ of the slope of the dotted line. Symbols as in top panel. Units for zonal (vertical) currents are $\mathrm{cm} \mathrm{s}^{-1}$ $\left(\mathrm{cm} \mathrm{day}{ }^{-1}\right)$. $(\bar{u} / L)+\left(\bar{w} / H_{\text {mix }}\right) \approx b \bar{u}+c$ (where $\mathrm{b}$ and $\mathrm{c}$ do not vary much among the models). The ratio between the variabilities of $-w\left(T^{\prime}\right)_{z}$ and $-\bar{u}\left(T^{\prime}\right)_{x}$, which quantifies the biases in the relative strength of the ENSO feedbacks can then be estimated through the ratio between the variabilities of $\left(a \bar{w} / H_{\text {mix }}\right) h^{\prime}$ and $(\bar{u} / L) T^{\prime}$. The latter is proportional to $\bar{w} / \bar{u}$ times the ratio between the variability of $h^{\prime}$ over that of $T^{\prime}$ in the central to eastern Pacific. The inverse quantity of the latter ratio is comparable to the $\alpha$ parameter quantifying what VPC05 call the "upwelling feedback," that is, upwelling and mixing of thermocline temperature anomalies. According to VPC05 (their Fig. 6), $\alpha$ shows little variation among the CGCMs for the Niño-3.4 region, except for GFDL CM2.1 and MRI CGCM2.3.2a. Note that for the Niño-3 region, most CGCMs (except the latter two and INM-CM3.0) exhibit an $\alpha$ of the same order as that of TAO data (or overestimate it by a factor less than 2), which suggests that the use of Niño-3.4 to estimate $T^{\prime}$ and $h^{\prime}$ in $\bar{w}\left[\left(T^{\prime}-a h^{\prime}\right) / H_{\text {mix }}\right]$ is valid to a large extent.

Under these assumptions, we argue that the balance between the zonal advective feedback and the thermocline feedback is mainly controlled by the mean tridimensional velocity field within the mixed layer (itself determined by the background state of the coupled system). To support this statement, we present a similar figure to Fig. 3 (top panel), considering only the mean zonal and vertical currents (Fig. 3, bottom panel).

Consistently with the simplifications proposed above, Fig. 3 (bottom panel) exhibits a distribution of the balance between zonal and vertical motion among the models similar to that in Fig. 3 (top panel) but emphasizes the differences between models. Again, three groups of models can be distinguished: the models located on the left of the flattest dashed line have strong mean equatorial zonal currents relatively to mean equatorial upwelling, in comparison to the ratio from SODA. Thus these CGCMs can be considered as dominated by the zonal advective feedback (group 1). Similarly, the models located on the right of the steepest dashed line can be considered as dominated by the thermocline feedback (group 3 ). The models located between the dashed lines have a fairly reasonable balance between zonal advective and thermocline feedbacks (group 2), with a $\bar{w} / \bar{u}$ ratio comprised in the arbitrarily chosen range of the multimodel mean $\bar{w} / \bar{u}$ ratio $\pm 33 \%$.

Only four models are classified differently by the top and bottom panels of Fig. 3: Institute of Atmospheric Physics (IAP) Flexible Global Ocean-Atmosphere-Land System Model gridpoint version 1.0 (IAP FGOALS-g1.0); UKMO Hadley Centre Global Environmental Model version 1 (HadGEM1); UKMO HadCM3; and CSIRO Mk3.0. In addition, the latter two exhibit in Fig. 3 (bottom 
panel) a stronger relative importance of vertical movements than the other models from the hybrid group (and the reference), which is consistent with their behavior in Fig. 3 (top panel). It was checked that considering SODA as the reference instead of the multimodel mean leads to the same classification for all models, as it exhibits a dynamical regime very similar to that of the ensemble mean.

On the other hand, according to this classification, the GODAS reanalysis belongs to the thermocline feedback regime category. This is partly due to the fact that GODAS spans the period characterized by enhanced ENSO activity and a warmer mean state that favors the thermocline feedback and slower time scales of interannual variability (An 2004; Moon et al. 2004). It is noteworthy that the SVD analysis (see section $2 b$ ) performed for SODA and GODAS over 1980-2001 reveals identical ENSO periods for both reanalyses (5.0 yr; not shown). In addition, the SODA heat budget performed over 19802001 leads to an increased relative contribution of the thermocline feedback compared to the budget over 19582001. Still, SODA in that case remains in the previously defined star group (hybrid feeback). This suggests that the differences between SODA and GODAS have to be related to either differences in forcings and/or model physics-parameterizations. It is known, for instance, that assimilation of temperature and salinity into an ocean model can make the currents less realistic (Burgers et al. 2002). Thus, reanalysis products based on different models and assimilation schemes like SODA and GODAS are likely to generate different velocity fields. Note, however, that SODA compares well with TAO ADCP data for the period from 1990 onward (Carton and Giese 2008). For this reason, and since SODA spans a longer period than GODAS (and since it is consistent with the CGCMs ensemble mean), it is retained as the "reference" in the rest of the paper. It is worth mentioning here that the choice of the reference only determines the limits between the different groups of models. It does not affect the differences among the CGCMs in regard to the relative importance of zonal and vertical advection terms in the heat budget and their biases diagnosed later in the paper.

To summarize, we have identified from the heat budget of each CGCM that biases in the simulated mean surface circulation $(\bar{u}, \bar{w})$ can be used to classify the CGCMs in groups relevant to their dominant ENSO regime. In the following, ENSO properties and model biases are interpreted in the light of this classification.

\section{c. Impact on the ENSO period}

In the following, we investigate to what extent characteristics of the ENSO mode can be related to the biases in the mean state identified above: as detailed in the introduction, it is expected that models with a dominant

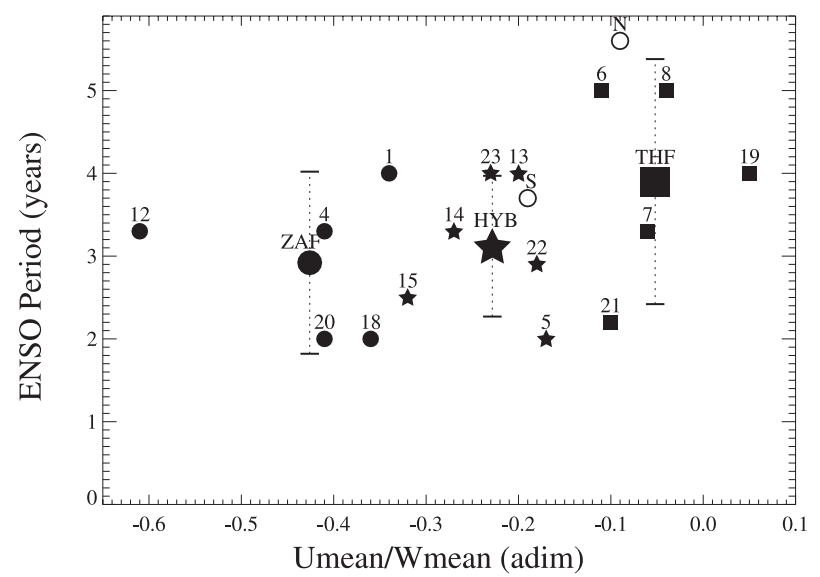

FIG. 4. Scatterplot of the ENSO period vs the $\bar{u} / \bar{w}$ ratio (see Fig. 3 , bottom panel) for the CMIP3 models. Model names are referenced in Table 1. The symbols are as in Fig. 3 (bottom panel) (see text). Unfilled circles are for the references: $\mathrm{S}(\mathrm{N})$ stands for SODA (GODAS). For each group [zonal advective feedback (ZAF), hybrid feedback (HYB), thermocline feedback (THF)], the larger symbol represents the mean ENSO period. Error bars correspond to the $95 \%$ confidence interval associated with the mean period. Units for the ENSO period are years. Units for $\bar{u} / \bar{w}$ are day s ${ }^{-1}$, i.e., the values have to be multiplied by 86400 for the ratio to be nondimensional.

zonal advective feedback have a short ENSO period, because of local surface wind-SST interactions due to "fast" advection in the mixed layer (e.g., Wang and An 2001; Fedorov and Philander 2001). On the other hand, models exhibiting a dominant thermocline feedback should have increased ENSO variability in the low-frequency range, because of the "slow" basinwide adjustment and an increased recharge/discharge time of equatorial upper-ocean heat content, accordingly to the recharge oscillator paradigm of ENSO (Jin 1996, 1997a,b).

Figure 4 presents the ENSO periods (Table 2) as a function of the $\bar{u} / \bar{w}$ ratio, that is, the relative strength of the zonal advective feedback versus the thermocline feedback. Although the models exhibit significant scattering, a tendency for increasing (decreasing) frequencies with a higher (lower) $\bar{u} / \bar{w}$ ratio is observed: consistently with earlier studies (Fedorov and Philander 2001; VPC05; G06), models dominated by the zonal advective feedback tend to simulate a higher ENSO frequency on average ( $2.9 \mathrm{yr}$, with $95 \%$ confidence in the 1.8-4.0 yr interval) than those dominated by the thermocline feedback (3.9 yr, with $95 \%$ confidence in the 2.4-5.4 yr interval). Assuming that multimodel behavior follows a Gaussian distribution within each group, the confidence intervals were derived from the standard error on the mean ENSO period for each group. The probability that the true mean period for group 3 is lower than that for group 1 is less than $20 \%$. In other words, the probability that the tendency mentioned above is significant is over $80 \%$. 
On the other hand, the mean ENSO period for group 2 lies in between group 1 and group 3 (3.1 yr, with 95\% confidence in the 2.3-4.0 yr interval), but is closer to the value for group 1 . In fact, the probability that the true mean period for group 2 is lower than that for group 1 is of the order of $35 \%$. This makes the distinction between groups 1 and 2 likely to be spurious (though it is more likely not to be so). Nevertheless, the arbitrary definition of the limits between groups (see previous section) might be able to explain this proximity between ENSO time scales from the zonal advective feedback and hybrid groups. Obviously, a more extended multimodel dataset comprising a larger number of members (ensemble simulations for each CGCM for instance) is required here in order to increase our confidence level in the ENSO period estimate. In addition, as underlined before, the relatively short length of the simulations does not allow taking into account the possible low-frequency modulation of ENSO: since it might impact the structure of the ENSO mode as suggested by Wittenberg (2009), this cautions against overinterpreting the aforementioned tendencies. However, the fact that the hybrid group follows the general tendency relating a shorter ENSO period with a higher relative strength of the zonal advective feedback tends to confirm our results. Note that similar tendencies were obtained when plotting the ENSO period against the ratio of the variability of $\bar{u}\left(T^{\prime}\right)_{x}$ over the variability of $w\left(T^{\prime}\right)_{z}$, as defined on Fig. 3 (top panel) (not shown).

One may note that the dominant ENSO period derived from SODA and ERSST (3.7 yr) is higher than that of group 2 but smaller than that of group 3 . The ENSO period from ERSST over 1880-2009 is shorter with a 20-yr running window than with a $15-\mathrm{yr}$ window (3.3 versus $3.7 \mathrm{yr}$ ). Hence, the difference in the width of the windows used for the CGCMs and for the references might explain - together with the bias of hybrid models toward the higher frequencies-why the ENSO time scale for SODA is "biased" toward the lower frequencies. Despite these discrepancies, the results suggest that a realistic representation of coupled ENSO feedbacks leads to realistic time scales of ENSO variability.

Note also that other biases might contribute to the heterogeneous ENSO periods found within each model category. For instance, Yu et al. (2009) showed that the biennial ENSO in the NCAR CCSM3.0 model is partly due to biases in the mean SST field of the Indian Ocean and in the Indian and Australian monsoon variability.

\section{Discussion}

\section{a. On the origin of mean circulation biases}

The previous section allowed relating biases in the mean surface circulation to both the dynamics of the ENSO

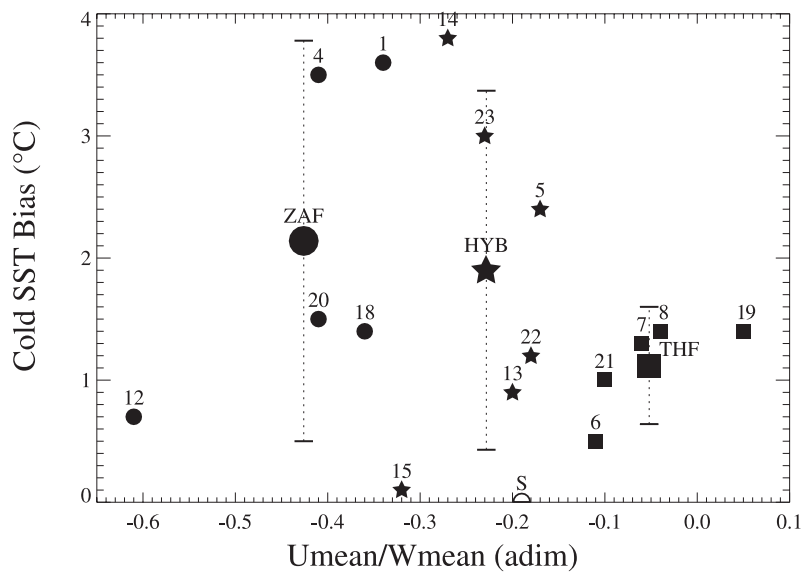

FIG. 5. As in Fig. 4, but for the mean SST bias in the western equatorial Pacific. SST was averaged over the Niño-4 region. Positive values correspond to a cold bias. Units are ${ }^{\circ} \mathrm{C}$.

mode (surface or thermocline driven) and the dominant time scale of ENSO in the IPCC models. However, the reason why a CGCM tends toward favoring the zonal advective feedback or the thermocline feedback remains unclear. In the light of the previous results, some clues are provided in order to understand the origin of these biases. As a first step, one can focus on the biases of $\bar{u}$, which exhibit the largest variability among the ensemble compared to $\bar{w}$ (Fig. 3, bottom panel). A similar reasoning can also be applied to $\bar{u}\left(T^{\prime}\right)_{x}$ (Fig. 3, top panel). This tends to confirm that biases in the representation of ENSO feedbacks are mainly controlled by biases in mean zonal currents in the central-western Pacific.

Biases in zonal surface circulation may imprint SST and subsurface temperature fields. As underlined by previous studies, a common bias of the CGCMs is their tendency to have an overestimated westward extension of the cold tongue. This is the result of the larger trade winds than observed for most models (G06; Guilyardi et al. 2009) and of the consequent overestimated mean zonal currents over the western Pacific. As a result of the westward displacement of the western edge of the cold tongue (and thus of the eastern edge of the warm pool), there is a tendency of the IPCC models to have a cooler warm pool than observed (Lin 2007).

To diagnose the mean temperature bias around the edge of the warm pool-located near the date line in the observations-in the models, the mean SST bias pattern was spatially averaged for all models in the Niño-4 box and examined against the $\bar{u} / \bar{w}$ ratio in the light of the classification presented above (Fig. 5). In spite of the rather heterogeneous behaviors of the models within each group, a tendency toward increased (damped) cooling associated with the increased dominance of the zonal advective (thermocline) feedback can be distinguished. 
On average, the models of group 1 exhibit a $2.1^{\circ} \mathrm{C}$ cold SST bias (with $95 \%$ confidence in the $0.5^{\circ}-3.8^{\circ} \mathrm{C}$ interval), the models of group 2 a $1.9^{\circ} \mathrm{C}$ cold SST bias (with $95 \%$ confidence in the $0.4^{\circ}-3.4^{\circ} \mathrm{C}$ interval), and the models of group 3 a $1.1^{\circ} \mathrm{C}$ cold SST bias (with $95 \%$ confidence in the $0.6^{\circ}-1.6^{\circ} \mathrm{C}$ interval). Similarly to Fig. 4 , the probability that the true mean of group 1 is lower than that of group 3 (group 2) is of the order of $20 \%(35 \%)$. This is consistent with the tendencies and confidence levels inferred from Fig. 4 and adds some degree of confidence to our results. Again, similar tendencies were obtained when plotting the SST bias against the ratio of the variability of $\bar{u}\left(T^{\prime}\right)_{x}$ over the variability of $w\left(T^{\prime}\right)_{z}$ (not shown).

One can note that all the models have a colder mean Niño-4 SST than SODA. It is suggested that this bias could result from a cooling due to the overestimated mean wind stress, and a warming/cooling associated with the nonlinear advection of the equatorial waves, as will be seen below. The systematic cold bias due to the wind forcing is thought to vary from one model to another and may explain the important variance of the total SST bias observed within each group. It is, however, striking that our classification in dynamical regime is consistent with the magnitude of the cold bias in the models.

As a consistency check, the mean bias of the $20^{\circ} \mathrm{C}$ isotherm depth in the Niño-4eq region was also examined, and a similar tendency is observed (not shown): on average, the thermocline is shallower in group 1 (group 2) than in group 2 (group 3), which implies that the biases in zonal advection are likely to impact the temperature not only at the surface, but also below the surface.

Nonlinear advection in the models is then diagnosed from the heat budget of the linear model simulations (section 2b). Indeed, Dewitte et al. (2007a) suggest that both climatological and anomalous westward advection of temperature anomalies have the tendency to cool the western-central equatorial Pacific. As a first step, the asymmetry of SST anomalies

$$
\text { asymmetry }=\frac{m_{3}}{m_{2}}
$$

was computed for all models in order to diagnose the El Niño-La Niña asymmetry: a positive asymmetry means stronger warm events than cold events. Likewise, a negative asymmetry means stronger cold events than warm events:

$$
m_{k}=\sum_{i=1}^{N} \frac{\left(x_{i}-\bar{X}\right)^{k}}{N}
$$

is the $k$ th moment where $\left(x_{i}\right)$ are the $\mathrm{N}$ observations of mean value $\bar{X}$.
An and Jin (2004) showed that SST skewness can be considered a proxy of ENSO nonlinearities in the eastern equatorial Pacific. Consistently with previous studies that analyzed the previous (An et al. 2005) and current generation of CGCMs (VPC05), we found that the models show a wide range of behaviors: some like CNRM-CM3 or MIUBECHOG are negatively skewed over most parts of the basin, while others like UKMO HadCM3 present a pattern that is closer to the observations, with positive values in the east and negative ones in the west (not shown). We find that most models tend to have a higher negative asymmetry than SODA on average over the tropical Pacific. In particular, SST in the western equatorial Pacific is generally more negatively skewed in the models than in SODA. This has to be related to the nonlinear zonal advection as shown below.

An et al. (2005) found that SST asymmetry increases linearly with the nonlinear dynamical heating $[\mathrm{NDH}=$ $\left.-u^{\prime}\left(T^{\prime}\right)_{x}-v^{\prime}\left(T^{\prime}\right)_{y}-w^{\prime}\left(T^{\prime}\right)_{z}\right]$ in the eastern equatorial Pacific. A similar result is found for our model ensemble, with a coefficient of determination $R^{2}=86.5 \%$-which is the proportion of variability in the model dataset that is accounted for by the linear statistical model (Steel and Torrie 1960)—indicating that most of the variability among the models can be explained by a linear fit (not shown). We also checked that NDH is dominated by nonlinear vertical advection in the eastern equatorial Pacific (An and Jin 2004), which leads to a linear relationship between SST asymmetry and nonlinear vertical advection in the Niño-3 region $\left(R^{2}=82.7 \%\right.$; not shown). Conversely, in the western equatorial Pacific where the thermocline is much deeper than in the east, nonlinear vertical advection is weaker at the surface and nonlinear zonal advection dominates NDH.

Figure 6 presents the scatterplot of nonlinear zonal advection versus SST asymmetry in the Niño-4eq region. Interestingly, a linear relationship is observed among the CGCMs, negative asymmetry increasing with nonlinear zonal advection. Two models do not fit with the linear trend (BCCR-BCM2.0 and INM-CM3.0), which is due to the large asymmetry simulated by these models. Their large negative-positive asymmetry may be due to other nonlinear processes in the tropical ocean-atmosphere coupled system than the advection processes considered here: vertical mixing in the ocean mixed layer (An and Jin 2004), the asymmetric response of the atmosphere to warm and cold SST anomalies (Kang and Kug 2002), the contribution of atmospheric nonlinearities (Kessler and Kleeman 1999; Perez et al. 2005; Philip and van Oldenborgh 2009, 2010), or the thermodynamic control on deep convection (Hoerling et al. 1997). Note also that the Niño-4 box may not be appropriate for quantifying asymmetry in the west for all the models. For instance, 


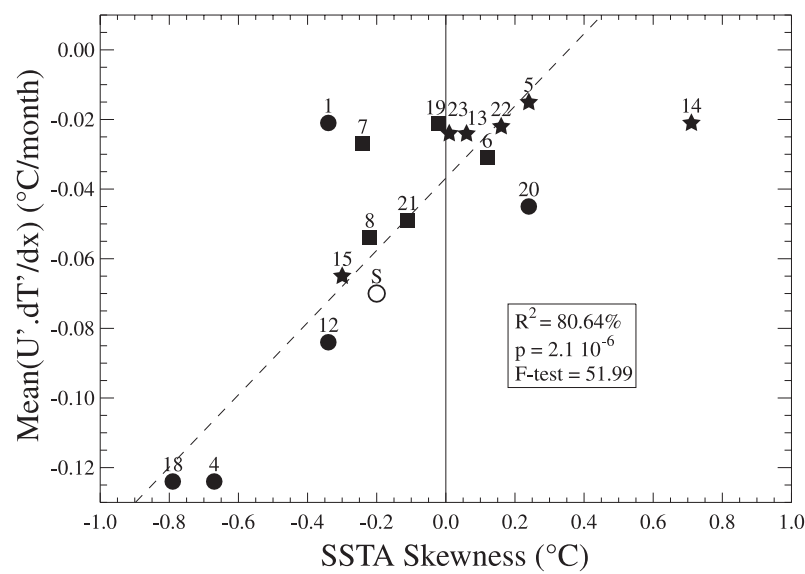

FIG. 6. Scatterplot of mean nonlinear zonal advection (averaged over Niño-4eq) vs asymmetry of SST anomalies (averaged over Niño-4) for the CMIP3 models. Model names are referenced in Table 1. Symbol are as in Fig. 5. The dotted line represents the result of the linear regression calculated for all models except BCCR-BCM2.0 and INM-CM3.0, with corresponding statistics marked on the plot. Units for nonlinear advection (asymmetry) are ${ }^{\circ} \mathrm{C}$ month $^{-1}\left({ }^{\circ} \mathrm{C}\right)$.

INM-CM3.0 has a peak of variability in the far western Pacific (Fig. 1q).

Considering the proposed classification in ENSO regime, we find that models dominated by the zonal advective feedback exhibit large negative asymmetry along with high nonlinear zonal advection, except BCCRBCM2.0 and MRI CGCM2.3.2a. For the latter, the prevalence of the zonal advective feedback relatively to the thermocline feedback is due to a stronger negative departure of vertical advection than that of zonal advection (Fig. 2), which explains why nonlinear zonal advection is lower and SST anomalies are positively skewed. Models dominated by the thermocline feedback show higher asymmetry and lower nonlinear zonal advection than SODA, except GFDL CM2.1, which has closer values, and GFDL CM2.0, which has slightly higher negative asymmetry. Surprisingly, all models having a hybrid feedback [except L'Institut Pierre-Simon Laplace Coupled Model, version 4 (IPSL CM4)] also show higher asymmetry and lower nonlinear advection than SODA: in most cases it is because the hybrid feedback is due to low mean vertical advection balancing the low zonal advection (CSIRO Mk3.0, INM-CM3.0, UKMO HadCM3; see Fig. 2). For UKMO HadGEM1, it is due to a nonlinear term of the opposite sign to the other zonal advection terms (Fig. 2). Interestingly, the ocean reanalysis almost lies on the regression line, supporting the interpretation presented above.

To summarize, it is proposed here that the mean cold bias around the edge of the western Pacific warm pool observed for all the models (Fig. 5) is induced by a combination of mean and nonlinear zonal advection terms, which are determined for most models by the privileged dynamical regime. It is then interesting to note that the biases in both the mean temperature field and the strength of nonlinear advection are consistent with the biases in mean zonal circulation. These results suggest the existence of a tropical rectification mechanism of ENSO dynamics by the privileged dynamical regime: the western equatorial Pacific cooling caused by zonal advection might lead to a strengthening of the mean trade winds through the linear response of the atmosphere to SST anomalies. Changes in the mean circulation may then feed back on the ENSO variability: in particular, the cooling tendency is associated with a shallower thermocline. This may result in enhanced anomalous transport in the upper layer and consequently increased anomalous zonal current anomalies that favor nonlinear zonal advection. In addition, according to Philip and van Oldenborgh (2009), the variability in nonlinear zonal advection in the Niño-4 region may originate from the nonlinear atmospheric response to SST anomalies in the eastern Pacific. On the other hand, some studies point out the possible role of the mean trade winds in the offequatorial region in the overestimation of zonal wind stress in the tropical Pacific (An and Wang 2000; Wang and An 2001). Further study is still needed in order to clearly document the respective roles of the tropics and the extratropics in the overestimation of the western Pacific zonal wind stress in the IPCC models.

\section{b. Differences with earlier attempts to identify ENSO feedbacks in CGCMs}

As mentioned in the introduction, this study is aimed at complementing those of VPC05 and G06 in regard to the determination of the privileged dynamical regime in the CMIP3 models.

VPC05 did not explicitly classify the models according to the ENSO regime. Instead, they provided a more qualitative interpretation of model behavior. Since no clear classification was provided, no relation can be inferred from their study between dynamical regimes and ENSO time scale. However, they did mention a group of models that is more wind driven, mainly via zonal advection, and stated that these models tend to have a short ENSO cycle. Among them, three models are analyzed by both VPC05 and the present study (CSIRO Mk3.0, INM-CM3.0, NCAR CCSM3.0): none of them are classified by the present paper as zonal advective feedback dominated. In fact, the feedback loops characterized by VPC05 do not account for the same processes as the ones identified here, as discussed below.

The main difference between the two studies comes from the formulation of the SST equation: while the 
dynamical model used here explicitly resolves the contributions of the tendency terms, the analysis proposed by VPC05 relies on the results of a linear model, which regresses the rate of SST change on zonal wind stress and thermocline depth anomalies (Burgers and van Oldenborgh 2003). Wind stress actually induces both horizontal advection in the mixed layer and upwelling across the thermocline, in addition to evaporation. Upwelling is then able to influence thermocline depth anomalies, which makes the separation between the respective effects of wind stress and thermocline anomalies on SST subject to debate. Hence an enhanced SST response to wind anomalies, for instance, does not necessarily lead to a short or to a long ENSO cycle, since it involves both zonal advection and thermocline feedbacks.

In addition, their study requires the linear assumption formulated in the SST equation. By doing so, they neglect the contribution of nonlinear advection, though it is known to be responsible for El Niño-La Niña asymmetry, extreme El Niño events, and mean state changes at decadal time scales (Timmermann and Jin 2002; An and Jin 2004).

Finally, we described the dependence of the balance between the ENSO feedbacks $\left[w\left(T^{\prime}\right)_{z} / \bar{u}\left(T^{\prime}\right)_{x}\right]$ on both the mean circulation $(\bar{w} / \bar{u})$ and the upwelling feedback $\alpha$ assessed by VPC05: their study does not take the former into account, despite its major role in the stability of ENSO in the CGCMs. Conversely, our study does not find any clear relationship between the ENSO regime-and thus the ENSO period-and the "wind feedback" as defined by VPC05. In the case of the three wind-driven short ENSO models mentioned previously: 1) INM-CM3.0 is characterized here by a quite realistic period ( $3.3 \mathrm{yr}$ ) and a hybrid ENSO regime, but comes with a very broad frequency band in VPC05 (1.5-9 yr), which implies much uncertainty on their estimate of the cycle length;2) the short ENSO cycle exhibited by NCAR CCSM3.0 might be due to teleconnections with dynamics from outside the Pacific (Yu et al. 2009), rather than the ENSO regime, which is diagnosed here as thermocline driven (section 3c); 3) the present paper does not specificly explain the short ENSO cycle for CSIRO Mk3.0 in spite of its realistic mean circulation (Fig. 3, bottom panel). However, it is one of the few CGCMs with an ENSO time scale that is way outside the usual range found within each category (Fig. 4).

On the other hand, 7 out of 12 CGCMs that both G06 and the present study analyze have coherent dynamical regimes, assuming that the separation between $\mathrm{S}$ and $\mathrm{T}$ modes based on the direction of propagation of SST anomalies can provide an estimate of the dominant feedback process. Among these models, four present a hybrid mode: INM-CM3.0, IPSL CM4, UKMO HadCM3, and
UKMO HadGEM1. Interestingly, they are among the most realistic models in terms of spatial and temporal structure of the ENSO mode, except INM-CM3.0, which features an unrealistic maximum of SST anomalies over the warm pool (Fig. 1q). However, no clear relationship is found between ENSO frequency and El Niño mode by G06, and only a slight tendency toward lower ENSO frequency by models exhibiting a T mode is observed.

The main differences with the present study are that no subsurface data are considered in G06, and the dominant feedback is diagnosed in G06 from the direction of propagation of SST anomalies. Most models exhibit an S mode or a hybrid mode. Even the observed data from after the 1976 climate shift feature a moderate T mode, consistently with the observed tendency toward westward propagation of SST anomalies before the shift and mixed eastward propagation and standing oscillations after the shift (An and Jin 2000; Wang and An 2001). This implies that the diagnostic proposed in order to separate models with an S mode and models with a T mode does not allow very marked categories, conversely to the present study (Fig. 3, bottom panel). In particular, few models exhibit a T mode, as a dominant thermocline feedback may still be associated with mixed eastward and westward propagation if the zonal advective feedback is also present.

Nevertheless, an inverse relation is observed by G06 for a subset of models between ENSO frequency and "interannual coupling strength" (i.e., the sensitivity of western Pacific wind anomalies to eastern Pacific SST anomalies), consistently with results from simple coupled models (Zebiak and Cane 1987; An and Jin 2000; Fedorov and Philander 2000). In fact, the coupling strength controls both the growth rate and the frequency of ENSO, as long as the relative contribution of the zonal advective feedback and the thermocline feedback is kept constant (An and Jin 2001). The relation found by G06 is therefore not necessarily contradictory with results from the present study, but it is not sufficient to explain the range of ENSO frequencies exhibited by the whole ensemble of CGCMs. For instance, MRI CGCM2.3.2a features a highfrequency ENSO cycle together with high coupling, possibly because of the dominant zonal advective feedback in this model.

\section{Conclusions}

In this study, 16 CGCMs of the CMIP3 multimodel ensemble were analyzed under preindustrial climate conditions in order to investigate the impact of the mean oceanic state over time scales of ENSO variability. Results of the SVD between wind stress anomalies and SST anomalies allow characterizing ENSO-like variabilities. A large diversity of characteristics is found between the 
models in terms of amplitude, pattern, and frequencies, consistently with previous studies (VPC05; G06; Capotondi et al. 2006).

A simple linear model of the tropical Pacific Ocean forced by winds from the CGCMs is used to estimate the zonal and vertical advection contributions to the rate of SST change in all the models. It reveals that the main source of error in the ensemble with regards to the dominant feedbacks (thermocline versus zonal advective feedbacks) can be inferred from the mean advection of anomalous temperature. A simple diagnostic based on the mean velocity fields in the surface layer is therefore proposed to classify the models according to their privileged ENSO regime. It leads to three groups of models characterized by their tendency to enhance one feedback over the other. The group of models presenting a balance between zonal and vertical advection comparable to SODA corresponds to the so-called hybrid feedback group and gathers the most realistic models in terms of the ENSO mode ocean dynamics.

ENSO frequencies are then analyzed according to the classification by the dominant feedback. Consistently with previous results from theory, observed data and modeling studies (Fedorov and Philander 2001; VPC05; G06), it is shown that models dominated by the zonal advective (thermocline) feedback have a short (long) ENSO cycle. Indeed, whereas an overly dominant thermocline feedback favors the slow time scale of variability, the dominance of the zonal advective feedback is associated with faster horizontal advection of SST anomalies, which rectifies ENSO-like variability toward more energy in the high-frequency band. Climate models from the hybrid group [CSIRO Mk3.0, Istituto Nazionale di Geofisica e Vulcanologia (INGV) ECHAM4, INM-CM3.0, IPSL CM4, UKMO HadCM3, and UKMO HadGEM1] have ENSO periods closer to the observations on average and are considered the most reliable for climate projections under increasing concentrations of greenhouse gases. Note, however, that this might be less true for CSIRO Mk3.0 and INM-CM3.0: in these two models, the SST variability associated with ENSO is displaced toward the western equatorial Pacific (Fig. 1). This may be the result of other mechanisms that were not explicitly taken into account in the present study, such as those contributing to the damping term of the SST equation, for instance (e.g., the cloud feedback in the western Pacific).

The rectification of ENSO variability by the dominant feedback process through the impact of the mean ocean state-particularly in the western Pacific-on the equatorial dynamics is further investigated in the CGCMs: mean temperature biases and asymmetry of SST anomalies-mainly driven by nonlinear zonal advection in the western equatorial Pacific_-are assessed.
Consistently with the results of Dewitte et al. (2007a), models dominated by the zonal advective (thermocline) feedback have a higher (lower) cold bias on average (though showing large variance from a model to another) and generally an increased negative (a damped negative or even a positive) asymmetry. The models with a hybrid feedback mostly exhibit a moderate cold bias and a slightly positive asymmetry of SST anomalies, which is caused for most of them by relatively low zonal advection (compensated by low vertical advection). It is suggested that the mean cold (warm) bias of the western equatorial Pacific associated with strong (weak) westward climatological zonal currents is caused by nonlinear advection.

Overall, this study provides a detailed methodology based on the use of a simplified tropical Pacific Ocean model for diagnosing the dominant mode of variability in the tropical Pacific. Strikingly, despite the numerous differences in model physics and parameterizations, a coherent classification of the models can be established based on the coupled instability theory: biases of the models can indeed be interpreted within these groups. It confirms the need of improving the mean climatological state simulated by state-of-the-art climate models, so as to improve the characteristics of simulated interannual variability under past/present climate conditions, and therefore our level of confidence in the climate projections for the next century.

This should provide useful information for the interpretation of the simulations with these same models considering an increase in $\mathrm{CO}_{2}$ concentration, in the context of assessment studies of the impact of climate change on ENSO variability. In particular, warming conditions are generally associated with a flattening thermocline- that is, a smaller zonal contrast of the thermocline between the warm pool and the cold tongue-and with a larger vertical gradient of temperature in the eastern Pacific mixed layer (An et al. 2008). Such changes may modify the prevalence of one feedback over the other. The latter tendency would tend to increase the strength of the thermocline feedback in the eastern Pacific. However, the decrease in the slope of the thermocline is accompanied for some models by a shallower thermocline and for others by a deeper thermocline in the eastern equatorial Pacific (Philip and van Oldenborgh 2006). Depending on the amplitude of ENSO variability, a deeper (shallower) thermocline in the east generally goes along with a reduction (increase) of the thermocline feedback in the eastern equatorial Pacific, because vertical displacement of the thermocline tends to have less (more) impact on the temperature of water that upwells into the surface mixed layer.

The combination of these different effects makes it difficult to speculate about the future evolution of the 
balance between the zonal advective feedback and the thermocline feedback under global warming. In addition, the simultaneous impact of the wind forcing on both feedback processes does not allow formulating a clear hypothesis to be associated with the observed reduction of the Walker circulation in the IPCC models considering the increase in $\mathrm{CO}_{2}$ concentration (Vecchi and Soden 2007). Indeed, the present study focuses on the biases in the oceanic component of the system. Yet, ENSO is a coupled ocean-atmosphere mode of climate variability, and the differences in atmospheric behavior between models can often be larger than those in oceanic responses. A limitation to this work is that the atmospheric response to SST anomalies and its effect on the zonal advective feedback and the thermocline feedback were not explicitly documented. Nevertheless, the former are driven to a large extent by the atmospheric part of the cycle, which implies that the atmospheric responses of the models were still implicitly taken into account by the methodology presented here. The possible changes of ENSO feedbacks under global warming and their relation with changes in both the mean surface winds and thermocline characteristics are topics for future research.

Acknowledgments. We are grateful to D. Battisti, J. Boucharel, M. Lengaigne, and Y. duPenhoat for fruitful discussions, to S. Bertrand and A. Chaigneau for their help with statistical computation, and to E. Guilyardi, S. Y. Philip, G. J. van Oldenborgh, and an anonymous reviewer for their help in the improvement of the original manuscript. We acknowledge the modelling groups the Program for Climate Model Diagnosis and Intercomparison (PCMDI) and the World Climate Research Programme's (WCRP's) Working Group on Coupled Modelling (WGCM) for their roles in making available the WCRP Coupled Model Intercomparison Project phase 3 (CMIP3) multimodel dataset. Support of this dataset is provided by the Office of Science, U.S. Department of Energy. GODAS data were provided by NOAA/OAR/ESRL PSD, Boulder, Colorado, from their Web site at http://www.esrl.noaa.gov/psd/. ERSST data were also provided by the NOAA/Earth System Research Laboratory (ESRL). We thank the Peru-Chile Climate Change (PCCC) program of Agence Nationale de la Recherche (ANR) for financial support. A. Belmadani benefited from an ATUPS grant provided by the Université Paul Sabatier (Toulouse, France), and from a Ph.D. scholarship received from Institut de Recherche pour le Développement (IRD) and Collecte Localisation Satellites (CLS). S.-I. An was supported by the National Research Foundation of Korea Grant funded by the Korean Government (MEST) (NRF-2009-C1AAA001-0093042).

\section{REFERENCES}

AchutaRao, K., and K. Sperber, 2002: Simulation of the El NiñoSouthern Oscillation: Results from the Coupled Model Intercomparison Project (CMIP). Climate Dyn., 19, 191-209.

$\longrightarrow$, and - 2006: ENSO simulation in coupled ocean-atmosphere models: Are the current models better? Climate Dyn., 27, 1-15.

Adler, R. F., and Coauthors, 2003: The Version-2 Global Precipitation Climatology Project (GPCP) monthly precipitation analysis (1979-present). J. Hydrometeor., 4, 1147-1167.

An, S.-I., 2004: Interdecadal changes in the El Niño-La Niña asymmetry. Geophys. Res. Lett., 31, L23210, doi:10.1029/ 2004GL021699.

—, and F.-F. Jin, 2000: An eigen analysis of the interdecadal changes in the structure and frequency of ENSO mode. Geophys. Res. Lett., 27, 2573-2576.

— , and B. Wang, 2000: Interdecadal change of the structure of the ENSO mode and its impact on the ENSO frequency. J. Climate, 13, 2044-2055.

— advective feedbacks in the ENSO mode. J. Climate, 14, 34213432.

— , and - 2004: Nonlinearity and asymmetry of ENSO. J. Climate, 17, 2399-2412.

— _ _ , and I.-S. Kang, 1999: The role of zonal advection feedback in phase transition and growth of ENSO in the CaneZebiak model. J. Meteor. Soc. Japan, 77, 1151-1160.

—, Y.-G. Ham, J.-S. Kug, F.-F. Jin, and I.-S. Kang, 2005: El Niño-La Niña asymmetry in the Coupled Model Intercomparison Project simulations. J. Climate, 18, 2617-2627.

_ J.-S. Kug, Y.-G. Ham, and I.-S. Kang, 2008: Successive modulation of ENSO to the future greenhouse warming. J. Climate, 21, 3-21.

Battisti, D. S., and A. C. Hirst, 1989: Interannual variability in the tropical atmosphere/ocean system: Influence of the basic state and ocean geometry. J. Atmos. Sci., 46, 1687-1712.

Behringer, D. W., and Y. Xue, 2004: Evaluation of the global ocean data assimilation system at NCEP: The Pacific Ocean. Preprints, Eighth Symp. on Integrated Observing and Assimilation Systems for Atmosphere, Oceans, and Land Surface, Seattle, WA, Amer. Meteor. Soc., 2.3. [Available online at http://ams.confex.com/ ams/pdfpapers/70720.pdf.]

Bretherton, C. S., C. Smith, and J. M. Wallace, 1992: An intercomparison of methods for finding coupled patterns in climate data J. Climate, 5, 541-560.

Burgers, G., and G. J. van Oldenborgh, 2003: On the impact of local feedbacks in the central Pacific on the ENSO cycle. J. Climate, 16, 2396-2407.

_- M. A. Balmaseda, F. C. Vossepoel, G. J. van Oldenborgh, and P. J. van Leeuwen, 2002: Balanced ocean-data assimilation near the equator. J. Phys. Oceanogr., 32, 2509-2529.

Capotondi, A., A. Wittenberg, and S. Masina, 2006: Spatial and temporal structure of tropical Pacific interannual variability in 20th century coupled simulations. Ocean Modell., 15, 274-298.

Carton, J. A., and B. S. Giese, 2008: A reanalysis of ocean climate using Simple Ocean Data Assimilation (SODA). Mon. Wea. Rev., 136, 2999-3017.

—, G. A. Chepurin, X. Cao, and B. S. Giese, 2000: A Simple Ocean Data Assimilation analysis of the global upper ocean 1950-95. Part I: Methodology. J. Phys. Oceanogr., 30, 294-309.

Derber, J. C., and A. Rosati, 1989: A global oceanic data assimilation system. J. Phys. Oceanogr., 19, 1333-1347. 
Dewitte, B., 2000: Sensitivity of an intermediate coupled oceanatmosphere model of the tropical Pacific to its oceanic vertical structure. J. Climate, 13, 2363-2388.

— with Cane and Zebiak's model and observed with satellite or in situ data. Part II: Model forced with observations. J. Climate, 9, 1188-1207.

—_, and G. Reverdin, 2000: Vertically propagating annual and interannual variability in an OGCM simulation of the tropical Pacific in 1985-94. J. Phys. Oceanogr., 30, 1562-1581.

—,- , and C. Maes, 1999: Vertical structure of an OGCM forced simulation of the tropical Pacific in 1985-94. J. Phys. Oceanogr., 29, 1542-1570.

—- D. Gushchina, Y. duPenhoat, and S. Lakeev, 2002: On the importance of subsurface variability for ENSO simulation and prediction with intermediate coupled models of the tropical Pacific: A case study for the 1997-1998 El Niño. Geophys. Res. Lett., 29, 1666, doi:10.1029/2001GL014452.

— C. Cibot, C. Périgaud, S.-I. An, and L. Terray, 2007a: Interaction between near-annual and ENSO modes in a CGCM simulation: Role of the equatorial background mean state. J. Climate, 20, 1035-1052.

—, S.-W. Yeh, B.-K. Moon, C. Cibot, and L. Terray, 2007b: Rectification of the ENSO variability by interdecadal changes in the equatorial background mean state in a CGCM simulation. J. Climate, 20, 2002-2021.

Fedorov, A. V., and S. G. Philander, 2000: Is El Niño changing? Science, 288, 1997-2002, doi:10.1126/science.288.5473.1997.

_ and _ 2001: A stability analysis of tropical ocean-atmosphere interactions: Bridging measurements and theory for El Niño. J. Climate, 14, 3086-3101.

Fjeldstad, J. E., 1933: Interne wellen. Geofys. Publ., 10, 3-35.

Guilyardi, E., 2006: El Niño-mean state-seasonal cycle interactions in a multi-model ensemble. Climate Dyn., 26, 329-348.

__, and Coauthors, 2004: Representing El Niño in coupled ocean-atmosphere GCMs: The dominant role of the atmospheric component. J. Climate, 17, 4623-4629.

- A. Wittenberg, A. Fedorov, M. Collins, C. Wang, A. Capotondi, G. J. van Oldenborgh, and T. Stockdale, 2009: Understanding El Niño in ocean-atmosphere general circulation models: Progress and challenges. Bull. Amer. Meteor. Soc., 90, 325-340.

Hirst, A. C., 1986: Unstable and damped equatorial modes in simple coupled ocean-atmosphere models. J. Atmos. Sci., 43, 606-630.

Hoerling, M. P., A. Kumar, and M. Zhong, 1997: El Niño, La Niña, and the nonlinearity of their teleconnections. J. Climate, 10, 1769-1786.

Jin, F.-F., 1996: Tropical ocean-atmosphere interaction, the Pacific cold tongue, and the El Niño-Southern Oscillation. Science, 274, 76-78.

, 1997a: An equatorial ocean recharge paradigm for ENSO. Part I: Conceptual model. J. Atmos. Sci., 54, 811-829.

_ 1997b: An equatorial ocean recharge paradigm for ENSO. Part II: A stripped-down coupled model. J. Atmos. Sci., 54, 830-847.

—_ and J. D. Neelin, 1993: Modes of interannual tropical oceanatmosphere interaction-A unified view. Part I: Numerical results. J. Atmos. Sci., 50, 3477-3503.

— backs within the equatorial ocean recharge oscillator model for ENSO. Geophys. Res. Lett., 26, 2989-2992.

_ J.-S. Kug, S.-I. An, and I.-S. Kang, 2003: A near-annual coupled ocean-atmosphere mode in the equatorial Pacific Ocean Geophys. Res. Lett., 30, 1080, doi:10.1029/2002GL015983.
Kanamitsu, M., W. Ebisuzaki, J. Woollen, S.-K. Yang, J. J. Hnilo, M. Fiorino, and G. L. Potter, 2002: NCEP-DOE AMIP-II Reanalysis (R-2). Bull. Amer. Meteor. Soc., 83, 16311643.

Kang, I.-S., and J.-S. Kug, 2002: El Niño and La Niña sea surface temperature anomalies: Asymmetry characteristics associated with their wind stress anomalies. J. Geophys. Res., 107, 4372, doi:10.1029/2001JD000393.

— S.-I. An, and F.-F. Jin, 2001: A symmetric approximation of the SST anomaly equation for ENSO. J. Meteor. Soc. Japan, 79, $1-10$

J.-S. Kug, S.-I. An, and F.-F. Jin, 2004: A near-annual Pacific Ocean basin mode. J. Climate, 17, 2478-2488.

Kessler, W., and R. Kleeman, 1999: Rectification of the MaddenJulian oscillation into the ENSO cycle. J. Climate, 13, 35603575.

Lighthill, M. J., 1969: Dynamical response of the Indian Ocean to the onset of the southwest monsoon. Philos. Trans. Roy. Soc. London., A265, 45-92.

Lin, J. L., 2007: The double-ITCZ problem in IPCC AR4 coupled GCMs: Ocean-atmosphere feedback analysis. J. Climate, 20, 4497-4525.

Meehl, G. A., 1987: The annual cycle and interannual variability in the tropical Indian and Pacific Ocean regions. Mon. Wea. Rev., 115, 27-50.

Moon, B.-K., S.-W. Yeh, B. Dewitte, J.-G. Jhun, I.-S. Kang, and B. P. Kirtman, 2004: Vertical structure variability in the equatorial Pacific before and after the Pacific climate shift of the 1970s. Geophys. Res. Lett., 31, L03203, doi:10.1029/ 2003 GL018829.

Neelin, J. D., D. S. Battisti, A. C. Hirst, F.-F. Jin, Y. Wakata, T. Yamagata, and S. E. Zebiak, 1998: ENSO theory. J. Geophys. Res., 103, 14 261-14 290.

Pacanowski, R. C., and S. M. Griffies, 2000: MOM 3.0 manual. GFDL Tech. Note, 682 pp. [Available online at http://www. gfdl.noaa.gov/cms-filesystem-action/model_development/ocean/ mom3_manual.pdf.]

Perez, C. L., A. M. Moore, J. Zavala-Garay, and R. Kleeman, 2005: A comparison of the influence of additive and multiplicative stochastic forcing on a coupled model of ENSO. J. Climate, 18, 5066-5085.

Philip, S. Y., and G. J. van Oldenborgh, 2006: Shifts in ENSO coupling processes under global warming. Geophys. Res. Lett., 33, L11704, doi:10.1029/2006GL026196.

, and - 2009: Significant atmospheric nonlinearities in the ENSO cycle. J. Climate, 22, 4014-4028.

$\longrightarrow$, and 2010: Atmospheric properties of ENSO: Models versus observations. Climate Dyn., 34, 1073-1091, doi:10.1007/ s00382-009-0579-7.

Picaut, J., F. Masia, and Y. du Penhoat, 1997: An advectivereflective conceptual model for the oscillatory nature of the ENSO. Science, 277, 663-666.

Ropelewski, C. F., M. S. Halpert, and X. Wang, 1992: Observed tropospheric biennial variability and its relationship to the Southern Oscillation. J. Climate, 5, 594-614.

Schopf, P. S., and M. J. Suarez, 1988: Vacillations in a coupled ocean-atmosphere model. J. Atmos. Sci., 45, 549-566.

Smith, R. D., J. K. Dukowicz, and R. C. Malone, 1992: Parallel ocean general circulation modeling. Physica D, 60, 38-61.

Smith, T. M., R. W. Reynolds, T. C. Peterson, and J. Lawrimore, 2008: Improvements to NOAA's historical merged landocean surface temperature analysis (1880-2006). J. Climate, $\mathbf{2 1}, 2283-2296$. 
Steel, R. G. D., and J. H. Torrie, 1960: Principles and Procedures of Statistics. MacGraw-Hill, 481 pp.

Suarez, M. J., and P. S. Schopf, 1988: A delayed oscillator for ENSO. J. Atmos. Sci., 45, 3283-3287.

Timmermann, A., and F.-F. Jin, 2002: A nonlinear mechanism for decadal El Niño amplitude changes. Geophys. Res. Lett., 29, 1003, doi:10.1029/2001GL013369.

Torrence, C., and G. P. Compo, 1998: A practical guide to wavelet analysis. Bull. Amer. Meteor. Soc., 79, 61-78.

Tourre, Y. M., Y. Kushnir, and W. B. White, 1999: Evolution of interdecadal variability in sea level pressure, sea surface temperature, and upper ocean temperature over the Pacific Ocean. J. Phys. Oceanogr., 29, 1528-1541.

Trenberth, K. E., and D. P. Stepaniak, 2001: Indices of El Niño evolution. J. Climate, 14, 1697-1701.

Uppala, S. M., and Coauthors, 2005: The ERA-40 Re-Analysis. Quart. J. Roy. Meteor. Soc., 131, 2961-3012.

van Oldenborgh, G. J., S. Y. Philip, and M. Collins, 2005: El Niño in a changing climate: A multi-model study. Ocean Sci., 1, 81-95.
Vecchi, G. A., and B. J. Soden, 2007: Global warming and the weakening of the tropical circulation. J. Climate, 20, 4316-4340.

Wang, B., and S.-I. An, 2001: Why the properties of El Niño changed during the late 1970s. Geophys. Res. Lett., 28, 37093712.

Wittenberg, A. T., 2009: Are historical records sufficient to constrain ENSO simulations? Geophys. Res. Lett., 36, L12702, doi:10.1029/2009GL038710.

_ - A. Rosati, N.-C. Lau, and J. J. Ploshay, 2006: GFDL's CM2 global coupled climate models. Part III: Tropical Pacific climate and ENSO. J. Climate, 19, 698-722.

Yu, J.-Y., F. Sun, and H.-Y. Kao, 2009: Contributions of Indian Ocean and monsoon biases to the excessive biennial ENSO in CCSM3. J. Climate, 22, 1850-1858.

Zebiak, S. E., and M. A. Cane, 1987: A model El Niño-Southern Oscillation. Mon. Wea. Rev., 115, 2262-2278.

Zhang, R.-H., L. M. Rothstein, and A. J. Busalacchi, 1999: Interannual and decadal variability of the subsurface thermal structure in the Pacific Ocean. Climate Dyn., 15, 703-717. 